\title{
Información electrónica en un mundo sin fronteras: tratamiento y análisis documental en los medios de comunicación
}

\author{
Juan C. Marcos Recio \\ Universidad Complutense y Universidad \\ Antonio de Nebrija, España
}

Traslaaivilizacónde librosepafilaunanueaea: laaparicónsimiltánæedeun nuevoalfabotounivessal (larepresentaaónnuméica) ydeunanuevaimprenta(dda dadenurasfuniones, asaber, laukiaidad, lainstantanidad, lacapacidaddedr plicaión y un costeprádicammtenulo), queda una idæa dela impatania dela reduaión

FedericoMayar Zaragza

\section{RESUMEN}

Elartículo describe las más recientes modificaciones que se prevén con el uso de las herramientas electrónicas: que el "periódico yo" (la información personalizada ) ya está en puerta y que en este tipo de servicio el propio usuario seleccionará electrónicamente lo que le interesa; que muy pronto el lector dejará de ser pasivo y gracias a su propia fuerza se dará su versión de los hechos; que el "nuevo comunicador" será una mezcla de periodista y documentalista que tendrá mucho que ver con la aparición, entre nosotros, de la información personalizada; que ya no se trata de enviarle "bits" a la gente sino que ésta pronto eligirá estos "bits".

Trabajo recibido el 4 denoviembre de 1999 *

Trabajo aceptado el 31 de enero de 2000
Palabras clave: Información electrónica, Análisis documental, Periodismo electrónico

\section{ELECTRONIC INFORMATION IN THE WORLD WTTHOUT FRONTIERS: DOCUMENTARY ANALYSISAND TREATMENT IN THE MEDIA JuAN C. MARCos-Recio}

\section{ABST RACT}

This article describes the most recent, foreseeable trends in the use of electronic tools. The "Me Newspaper" (websites with personalized information) is just around the comer. This kind of service will allow user to select what interests him, a phenomenon that suggests that the user will no longer be a passive receptor, but rather and active creator of versions of 
events. The "new communicators" will be a hybrid of the journalist and the documentary maker and thereby exercise considerable influence in the appearance of personalized information.

Key Words: Electronic Information, Document Analysis, Electronic Journalism

\section{INTRODUCCIÓN}

Gucede con frecuencia que la ciencia va por delante de la realidad y, por este motivo, $\checkmark$ se habla de ciencia ficción, cuando en realidad deberíamos utilizar la expresión futuro inmediato. Esto mismo sucede actualmente en los medios de comunicación. Sin darnos cuenta, se está hablando de información y documentación electrónica, de periódicos electrónicos, sin precisar quéva a significar esto dentro de las empresas de comunicación, paralos propios profesionales, sus lectoresy anunciantesy, sobre todo, si ésta va a ser la revolución definitiva en el campo de las comunicaciones.

Como acontece a lo largo de la historia, de los errores también se aprende y bueno sería que se tomaran en consideración desde el principio para evitar que muchas empresas y, sobre todo, muchos profesionales de los medios de comunicación se vieran desplazados de su puesto de trabajo, lo mismo que sucedió con lallegada de la linotipia y, años más tarde, con la presencia en las redacciones de los vídeo terminales, que apartaron poco a poco a los linotipistas, ya que el redactor pudo elaborar su propia información sin tener que depender de un componedar. Es sa guerra que le costó el cierre a varios periódicos en Estados Unidos, algunos de ellos importantes, debe servir de ejemplo para no cometer errores parecidos. Aunque de todo se puede aprender, como señala el pensador francés de origen ruso K oyre:

\section{La historia del pensamiento científico tiende a captar el camino seguido por este pensamiento en el movimiento mismo de su actividad creadora [...] Hay que estudiar los errores y los fracasos con tanto cuidado como los triunfos. 1}

D e los errores pasados la informática aprovechó su parte positiva para colocarse en la parrilla de salida del siglo XXI, en un puesto de honor. Mirando atrás, alos albores de una revolución que fue lenta, si consideramos que han pasado ya cincuenta años de los primeros ordenadores, hay que señalar que de aquellas máquinas mastodónticas, pesadas, lentas y rudimentarias se ha pasado al otro extremo de la balanza. A hora son pequeñas, manejables, rápidas, seguras y, sobre todo, personales, es decir utilizadas para satisfacer las necesidades de cada persona, no sólo de las empresas. La auténtica revolución informática, dicen los expertos, está por llegar, pero este final de milenio ha supuesto un ascenso imparable, gracias a las posibilidades que han ofrecido los ordenadores, aunque aún encuentren enemigos que apuestan por el uso de tecnologías tradicionales, más por sentimentalismo, que por razones prácticas.

1 Alexandre Koyre: Esudios dehistaria dd pensamientodentífica Madrid: Siglo XXI, 1990, p. 7. 
En realidad, existe un sentimiento generalizado y mayoritario en relación con el uso de los ordenadores en todos los campos científicos, también en los domicilios, facilitado por el descenso de los precios y por una mayor facilidad en sus sistemas de trabajo. Pero el pleno uso de estas máquinas está por llegar, puesto que aún existen problemas a la hora de utilizar los programas y que muy pocas personas conocen todos los que existen. La tendencia empresarial camina hacia una unificación de lenguajes que le permitirá a los usuarios acceder a muchos trabajos de forma más sencilla.

Y además del ordenador, los medios de comunicación dispondrán de otros elementos de ayuda, como el satélite, el cable y las posibilidades que ofrece la telefonía sin hilos. Pero todos los avances tecnológicos no servirán si no se humanizan y se permite al usuario-lector tener el control de una parte de la información.

El triunfo de la informática ha permitido que la mayoría de los campos del saber avancen a un ritmo hasta ahora nunca antes considerado, pero es quizás en los medios de comunicación donde esta herramienta ha supuesto una mayor dosis de actividad. En este sentido la documentación también se ha beneficiado, puesto que ha permitido seleccionar y gestionar tanto la propia información como la mayoría de actividades administrativas y de control que se llevan a cabo en un centro de documentación. Aunque a los másjóvenes les parece que los ordenadores han estado ahí desde siempre, la realidad es muy distinta, hasta el punto de que aún no han cumplido su primer centenario.

No existe un consenso general, pero la mayoría de los autores atribuyen el invento del ordenador al matemático Howard Aiken, quien en 1937, ayudado por algunos estudiantes, logró ensamblar un primer equipo, aunque hasta 1943 y en colaboración con IBMno ensambla su Mar I, un ordenador de dimensiones impensables hoy en día: "La máquina era un auténtico dinosaurio de quince metros de longitud por dosymedio de altura. Teníaalrededor de 750.000 componentes conectados por 300 kilómetros de cable y 3.300 interruptores electromecánicos." 2 Hay quien atribuye la paternidad deesteinvento, que revolucionó el final de este siglo y convivirá en el que viene como un aparato más de la casa, a John V. A tanasoff, quien también en 1937 andaba ideando una máquina que efectuara ciertos cálculos.

Sea como fuera, el 15 de febrero de 1946 se presentó públicamente el primer ordenador electrónico , AENIAC(EletronicNumerical IntegratorandCalaulatar). D e similares medidas al anterior, no es hasta 1951 cuando se muestra el primer ordenador comercial, que signa un proceso en lavidaindustrial y comercial que algunos autores han definido como una nueva revolución: la revolución informática en todos los campos. Este ordenador se conoció como UNIVAC(Universal AutomaticComputer) y su primera misión fue hacer el censo de Estados Unidos, que se había elaborado un año antes.

El paso decisivo se produjo en 1959 al descubrirse el circuito integrado, que permitía instalar muchos transmisores dentro de un chip, lo que redujo el tamaño delos

2 José Terceiro: SociedadDigital. De homosapiensal homodigtalis Madrid: Alianza Editorial, 1996, p.33. 
ordenadores y aumentó considerablemente su velocidad. Q uince años después, en 1964, una compañía que hasta entonces se dedicaba a realizar trabajos para el estado, abrió su mercado a las empresas con la creación de un modelo de la serie 360 . D urante la década de los sesenta, los ordenadores siguieron teniendo medidas excesivas para introducirlos en un mercado competitivo.

Los mainframes utilizados para las primeras bases de datos, eran similares a los que se empleaban en las empresas que apostaban ya por la informática. Fue, sin embargo, en los años setenta cuando se produjeron los avances más significativos en cuanto a velocidad de trabajo y capacidad de memoria. A partir de entonces, y gracias a los lenguajes de programación que fueron surgiendo, los ordenadores personales comenzaron a ser familiares en las empresas.

En los noventa, la capacidad, el uso y los precios han variado tanto que es raro el domicilio que no cuenta ya con un ordenador, y en breve sucederá como con la televisión, que se dispondrá de más de una terminal, como señala Terceiro: 3 "La evolución del ordenador a lo largo de las cuatro décadas, de los sesenta a los noventa, da lugar a cuatro nuevos paradigmas que se suceden a lo largo del tiempo: el procesamiento por lotes, el tiempo compartido, el PC y las redes."

En esta línea evolucionó el trabajo de hombres como Bill Gates y Paul Allen, en Microsoft, o de Steve P. Jobs y Stephen Wozniak, en Apple. Los primeros convencieron a IBM para que introdujera en sus ordenadores el D O S (Disk OpeatingSystem), lo que leallanó el camino a una delas empresas más poderosas del mundo y permitió una diferente organización del trabajo en casi todos los campos.

En esta etapa hay que pensar que laimplementación del hardwarey safvarefue fruto de una investigación profunda por parte de varias empresas que vieron una gran oportunidad denegocio. El fin último, una vez conocidala buena acogida de los Macintosh de Apple, fuela simplificación del uso de los ordenadores y la posibilidad de unificar lenguajes para acceder mejor a la información.

También el mundo de la comunicación se benefició de los ordenadores, aunque éstos llegaron en una etapa muy posterior. Primero fueron las editoriales las que emplearon esta máquina para ajustar el texto y para componerlo, sólo años más tarde comenzaría su uso en la empresa periodística.

El futuro de los ordenadores no se encamina hacia su uso en la redacción y el centro de documentación, ni a cumplir más funciones dentro de una empresa. Lo importante en la primera década del tercer milenio serán las muchas tareas en las que tomará parte, sobretodo en el mundo de la comunicación, en el quealgunos piensan que las noticias de los periódicos son mucho más profundas que las de la televisión, por ejemplo, porque permiten una lectura detenida, mientras que las que observamos en los medios audiovisuales, si no las grabamos podemos perder parte del contenido. En esta línea de trabajo, el ordenador del futuro nos resolverá estos problemas, como ha profetizado Negroponte: "La respuesta consiste en crear ordenadores para filtrar,

$3 \quad$ Ibidam $\mathrm{p} 39$. 
clasificar, seleccionar y manejar multimedia en beneficio propio; ordenadores que lean periódicos y miren la televisión por nosotros y que actúen como editores cuando se lo pidamos." " Nicholas Negroponte apostó por los bits frente a los átomos, según explica en su libro El mundodigtal, pensando en los avances que aportará la tecnología digital frente a la analógicay, sobre todo en el ancho de banda que permitirá que circulen por un canal más contenidos informativos: no solo textos, sino también imágenes y sonido.

El problema está en plantear el uso de lainteractividad y el delas herramientas informáticas. Así, a juicio de Franquet:

El final del siglo XX, desde el punto de vista tecnológico, se recordará como período de transición, donde la cultura matriz analógica empezó a ceder terreno a una cultura dominada por la señal digital[...] Estos medios se catalogan con una etiqueta-paradigma: la interactividad. ${ }^{5}$

D e esta forma, los medios de comunicación cambian radicalmente, ya que la información electrónica elaborada en línea y recibida de esta forma va a permitirle al lector formar parte de ella, bien como especialista, o bien como usuario conocedor de esa disciplina. La interactividad afecta también a la documentación, porque permite respuestas de información matizadas.

\section{NUEVAS TECNOLOGÍAS DE LA INFORMACIÓN}

En este sentido, la interactividad, aun en sus comienzos, como explica la catedrática de Comunicación Audiovisual de la Universidad Autónoma de Barcelona, Rosa Franquet, será necesaria, por no decir obligatoria, cuando la mayoría de los productos (es decir, el texto, la música, la palabra, la fotografía, el video, los gráficos, etcétera) se envíen y se reciban por ordenador. Podríamos decir que a estas alturas de final de siglo, esta propuesta ya es firme, gracias a las técnicas de compresión y descompresión, incluso cuando nos referimos a imágenes.

En la misma línea que el profesor Negroponte, Rosa Franquet apuesta por los bits porque éstos permiten mezclar, manipular y hasta copiar la información y, lo que es más importante, se podrá consumiroalmacenaresta información bajo distintas formas, dependiendo de las necesidades del usuario. Lo aceptable de esta propuesta es que los servicios serán más selectivos, de ahí que será el mismo sistema el que "nos ayude a elegir el contenido y el continente de la información que deseamos actualizar", como atestigua Franquet. Así pues, estamos hablando de ofrecer más información y en mejores soportes, lo que permite hablar de información personalizada o información electrónica seleccionada por el propio usuario. Ahora, ya no se especifica el soporte, sino el contenido, porque los avances tecnológicos se habrán simplificado tanto que la información será lo más importante:

4 Nicholas Negroponte: El mundbdigtal. Barcelona: Ediciones B, 1995, p. 35.

5 Rosa Franquet: "La saandida digtal: Escenarios deuna transfomacónacderada". En: Comunicacón Social 1995/ Tendanias, Infomes Anuales deFundesco Madrid, p. 285. 
A éste - usuario- no leva a importar cuál es el método de transporte utilizado por el emisor, sólo le interesa aprovechar las ventajas de un consumo versátil en forma de periódico electrónico, emisiones de radio 0 televisión, papel impreso, vídeo, fax, audio, etc. El sometimiento a un determinado soporte se habrá terminado y también la obligatoriedad de consumir el mensaje en el mismo orden en que fue transmitido. ${ }^{6}$

D urante varias décadas, las escuelas y facultades de periodismo defendieron la idea de McLuhan de que e medioes e mensaje Hoy, con las nuevas tecnologías, hay que pensar que lo necesario es el contenido, ya que los medios por los que éste se recibe pueden ser múltiples. Así lo asevera el profesor Negroponte:

En un mundo digital el medio no es el mensaje, sino una encarnación de éste. Un mensaje puede tener varias encarnaciones que deriven de manera automática de la misma información. ${ }^{7}$

Es una cuestión de selección. La información nos llega a través de un solo canal. A provechando el ancho de banda, el usuario o el ordenador será el encargado de hacer una selección. Es una tarea documental selectiva, como paso previo a un perfil del usuario que recibe un producto a través de la $\mathrm{D}$ ifusión Selectiva de la Información -D SI- . Este proceso le da una importancia decisiva al ordenador, algo que ha tardado en hacerse presente en los centros de documentación dada la dificultad que tiene una máquina para establecer criterios propios. Si la propuesta es hacer una selección de la información bajo unos parámetros determinados, también se podrá aprovechar para la selección documental, pero si además se les exigen otras funciones, está por verse si éstas serán efectivas, a pesar de que Negroponte considere que esta propuesta se puede llevar a cabo con la realidad digital y el ancho de banda:

Ser digital cambiará la naturaleza de los media. Se invertirá el proceso de envío de bits a la gente por un proceso en el que las personas o sus ordenadores serán los que elijan esos bits. ${ }^{8}$

En este sentido debemos encuadrar el concepto de información electrónica, es decir, la posibilidad de elegir entre muchas informaciones, sin vernos obligados a leer aquello que no nos interesa. Es la información personalizada en un mundo en el que ya es imposible controlar los diferentes aspectos sobre los que una persona quiere saber, leer o entretenerse. Habrá, por tanto, que cambiar los criterios de selección y ajustar los contenidos personales, algo que las nuevas tecnologías pueden aportar al disponer de un canal de banda ancha por medio del cual pueden transmitir diferentes aspectos informativos, educativos, de ocio, etcétera.

Este camino, que ahora comienza a andarse, se mueve de forma acelerada, como la propia energía que transforma las Nuevas Tecnologías de la Información. Será difícil calcular el número, porque cada día aparece una nueva publicación en formato

6 Rosa Fanquet: La saaudida digtal..., p. 285.

7 Nicholas Negroponte: Unmmobdigtal ... , p. 93.

8 Nicholas Negroponte: Unmundodigtal ... , p. 93. 
electrónico, pero lo destacable es que las empresas de comunicación se han decidido por ofrecer el producto periódicodectrónico como opción junto al periódico impreso. El tiempo dirá cuál de los dos termina imponiéndose, pero las expectativas son claras a favor del peicódicodetrónicoo del peiódicoyo o de la información personalizada, sea cual fuere el soporte a través del cual llegue.

D eesta forma, en diciembre de 1995 se hablabaya de 500 periódicos electrónicos en el mundo, según una información publicada en el diario ABC: "Hay ya unos 500 periódicos electrónicos, mientras que hace un par de años eran prácticamente inexistentes; los observadores del sector prevén que la cifra se multiplique por tres 0 cuatro en los próximos dos años." 10 Las expectativas planteadas por ABC, uno de los periódicos que ha apostado por las Nuevas Tecnologías y que ya ofrece su producto informativo a través de Internet, se han quedado cortas. Meses después, según datos facilitados por el profesor A umente las cifras seguían aumentando: "para este año se calcula que van a existir más de 2.000 periódicos electrónicos." 11

D ela misma opinión era el investigador mexicano y premio Fundesco de Ensayo 1995, Raúl Trejo, quien según sus propias estimaciones, afirma que al finalizar 1996 habría unos 2000 periódicos en Internet. Y, como sucede con otros factores de la vida, Estados Unidos, al comenzar 1996, contaba con la mitad delos periódicos introducidos en la Red. En el origen de este tipo de prensa están dos periódicos: SanJoś MearryNeusy NewYok Tims este último, siempre a la vanguardia y apostando por ofrecer mejores servicios a sus lectores, fue uno de los que más creyó en la información electrónica. Además creó un espacio diario en Ameica Onliney posteriormente presentó su World Wide Web. Y lo hizo siguiendo un modelo que ofrecía información rápida y fácil de manejar, algo que puede interesar al lector y que éste está dispuesto a pagar. Mediante un resumen diario por fax y pagando una cuota, el periódico podía ser sacadode la Red y leído mediante un decodificador de textos.12

Esta manera de fabricar y vender un periódico electrónico se aplicó, con algunas variantes, en el resto de servicios de información (tipo periódico electrónico) que realmente tenía algún interés dentro de Internet. Así, TheNewYodk Times terminó cobrando una cuota mensual para los usuarios que deseaban tener acceso a su páginaWeb. D e esta forma, todos aquellos contenidos que puedan interesar al navegante empiezan a ser objeto de pago; cuando mucho durante un período de tiempo de no más allá de un mes, el producto informativo se presentará de forma que todos puedan acceder a él y conocerlo, para posteriormente pedir una clave de acceso y un pago previo a su consulta.

9 Aún no se pueda considerar como tal, porque le falta contenido y presencia tecnológica.

10 ABC, 31-12-1995.

11 Conferencia celebrada en el D epartamento de Biblioteconomía y D ocumentación de la Facultad de Ciencias de la Información, el 29 de febrero de 1996.

12 Los conceptos "sacado, bajado, tomado" y otras acepciones similares son empleados por los investigadores cuando hacen referencia a una cita tomada de Internet. En este artículo emplearemos la referencia "bajado" de la red. 
Hay que matizar todas estas consideraciones, porque antes debemos circunscribir el marco en el que se va a mover el periodismo electrónico, algo que en España está siendo considerado más como una mera copia del periódico editado en papel, que como un verdadero producto informativo trasmitido por ordenadory recibido de forma personal por cualquiera de los métodos que permite la telefonía o el satélite.

Las previsiones de futuro en este campo, como en cualquier otro, son difíciles de evaluar, pero todo dependerá de la evolución delas tecnologías. A mayornúmero de ordenadores personales en casa, más posibilidades habrá de que hablemos de un producto informativo propio, recibido en ordenador, un periódicoyo como explica el profesor y director del Lab, del Instituto Tecnológico de Massachusetts, Nicholas Negroponte.

\section{INFORMACIÓN Y DOCUMENTACIÓN ELECTRÓNICA}

Es a partir de la segunda mitad de este siglo cuando podríamos pensar que el concepto de información sufrió su mayor transformación, hasta llegar a la apreciación de que los contenidos que transporta son considerados como poder. De ahí nació el cuarto poder, que tenía a los periódicos como fuerza social y política, algo que decaerá cuando la información ya no sólo sea controlada por los Estados o las empresas de comunicación, sino cuando cualquier persona pueda acceder desde su casa a una gran cantidad de datos, no sólo los que están dentro de las bases de datos, sino también en los periódicos elaborados por una colectividad o por una persona.

Hasta entonces, algunos avances técnicos habían permitido enviar y recibirinformación a distancia, pero con la llegada de los primeros ordenadores a las mesas de redacción, el significado y, so bre todo, los resultados obtenidos en el tratamiento informativo empezaron a ser totalmente diferentes. Por supuesto, la documentación también participa del proceso informativo, aunque en una fase posterior. Aún nos encontramos acoplando las posibilidades técnicas a la información, y desde el centro de documentación se observa y se entregan las referencias en el soporte tradicional, es decir, el papel.

El origen de la información electrónica tenemos que situarlo tras la aparición del cable como elemento transmisor a distancia, fundamentalmente el telégrafo y el teléfono, ya que todavíano existía la transmisión mediante satélite. Es en aquellos momentos cuando la información deja de ser local y abre sus puertas a otros temas que no tienen quever directamente con la comunidad a la que sirve el periódico. El concepto de actualidad, consecuentemente, también sufre algunas modificaciones, en el sentido de que lo lejano es ahora más cercano e, incluso, en que los periódicos disponen de más posibilidades para alcanzar un mayor número de venta de ejemplares al retrasar el cierre y ofrecer la información más próxima al lector, puesto que el periodista puede enviar la noticia más tarde y más lejos. 
La documentación se fue adaptando de forma paralela. Si estos nuevos sistemas de envío de información nos permitían estar más cerca del hecho noticioso, al centro de documentación se le iba a exigir la misma respuesta para completar de forma satisfactoria el proceso. Pero la realidad era otra. La ayuda necesaria que podría aportar el documentalista no se constataba en documentos, porque no se disponía de las herramientas adecuadas, por lo que en muchos casos el documento llegaba tarde o no se conseguía.

Si la primera mitad del siglo actual viene a constatar un asentamiento de lo que supuso la presencia de abundante información contada por teléfono - no escrita aún como si habláramos de un periódico personalizado- , los años siguientes al final de la Segunda Guerra Mundial dan paso a un ensayo generalizado y a la implantación de elementos técnicos en los periódicos. Se pasa, en apenas 20 años, de las viejasy siempre eternas máquinas de escribir a los primeros ordenadores, aunque éstos sólo permitían realizar unas pocas funciones y casi siempre tarde en el campo propiamente dicho de la información, pues antes habían sido instaladas en otras secciones, casi siempre en la administración, donde ya contaban con programas de contabilidad para gestionar los gastos e ingresos de la empresa. No se puede decir lo mismo de los procesadores de texto que aún tardaron en surgir, por lo que hubo que ir compaginando la máquina clásica con los primeros teclados. Cuando los editores se dieron cuenta de las posibilidades que tenía el ordenador, sobre todo en la clasificación de los anuncios por palabras, que tantos problemas planteaba en los grandes periódicos, empezaron de inmediato a introducir ordenadores en la redacción.

D entro de esa convivencia, los ordenadores terminaron desplazando alas máquinas de escribir dada la rapidez de los primeros para hacer correcciones, ajustar el texto, ensamblar otros textos, etcétera, aunque los redactores se dieron cuenta, también por primera vez, que ellos ya no eran quienes controlaban el sistema, sino un experto en informática. Así pues, los medios técnicos hicieron posible la llegada a mayor velocidad y de mayor cantidad de información a la redacción, con lo que el trabajo también aumentó en el centro de documentación, aunque no se buscaron más soluciones que aumentar el número de empleados.

Mucho antes de aquellos emisarios que empleaban el caballo, el vapor o el tren, el hombre ya había comenzado a intercambiar ideas e información a distancia, bien con la fuerza de su voz, hasta donde los límites físicos llegaban, o bien, empleando otros sistemas, tales como el ruido de un tambor o las señales de humo. Pero nada de esto, que en sus tiempos fue efectivo, se puede comparar con la llegada del ordenadory con las posibilidades de comunicarse a distancia mediante un cable 0 un satélite. No habríamos llegado a la información electrónica y, consecuentemente a uno de sus productos: el periódico electrónico, si lainformática no se hubiera desarrollado a gran escala y con mucha rapidez. D e esta simbiosis: informática y telecomunicaciones, nace la información a distancia, importante en el mundo de la comunicación, pero no menos en el empresarial, si consideramos el valor que han adquirido las empresas que trabajan en este sector. Pero mayor es el logro en el 
campo de las telecomunicaciones, donde la información ha dejado de ser el cuarto poder para convertirse en el primero. En efecto, la información se considera el motor de la civilización, sobre todo después de que los Estados Unidos, a través de un proyecto de William Clinton y Al Gore, decidieran que la información sería la materia prima imprescindible para el siglo XXI, y colocaran las bases para lograrlo invirtiendo una parte importante de su presupuesto en apoyar las Nuevas Tecnologías de la Información para que todos los estados, y de esta forma sus ciudadanos, tuvieran las mismas oportunidades. ${ }^{13}$

Esto no es del todo cierto, porqueacceder a esa información electrónica no es fácil ni barato, si pensamos en aquellas personas que carecen de la formación técnica precisa para llegar a ella y, sobre todo de una situación económica favorable para comprar los equipos necesarios y trabajar con este tipo de información. En esta línea, los Estados Unidos invierten en las universidades con el fin de potenciar la información, al considerar a estos centros como la principal fuente que dispone de amplios contenidos. El siguiente paso fue popularizar la información y llegar al mayor número de personas, pero ya con un recorte en los presupuestos, de tal forma que los usuarios sean ahora quienes paguen una parte 0 el total de los servicios que consultan y que tienen valor; porque hemos de recordar que no todo lo que está en Internet ${ }^{14}$ merece la pena.

Así, las Nuevas Tecnologías de la Información (NTI) abarcan un amplio elenco de nombres, tales como teledocumentación, teleinformación, telemática..., cuyo fin último es enviar, recibiry almacenarinformación sin pérdida de tiempo. Además, se ha superado una barrera física, puesto que la distancia se reduce con las posibilidades que ofrecen las NTI.

D e forma paralela, las ciencias que actúan de forma directa y que trabajan con la información vieron modificados sus hábitos. Así, bibliotecas y centros de documentación fueron los primeros en beneficiarse en cuanto a recuperación y préstamo de la información, luego las empresas periodísticas y el resto de las empresas, y posteriormente el último nivel, el personal, que permite la comunicación desde el domicilio de cada usuario.

La información electrónica, frente al concepto de manual, puede definirse como aquella que es tratada, analizada y enviada empleando soportes magnéticos, en un primer momento, y ópticos, más adelante, con el fin de almacenarla para ser leída y recuperada por un ordenador. ${ }^{15}$

13 Precisamos aquí el apoyo que prestó el gobiemo americano a Internet en sus comienzos, así como el desarrollo llevado a cabo desde algunas universidades de ese país.

14 Constatamos aquí una realidad llevada a cabo por empresas e instituciones educativas en Estados Unidos, que en su origen alimentaron Internet como si de un gran centro de información y documentación se tratara.

15 Es fundamental precisar la idea de recuperación, pues los documentalistas ya no tendrán como misión importante facilitar una información que pueden obtener los usuarios de manera sencilla, más bien tendrán que buscarla, seleccionarla y analizarla. 
El proceso técnico exige un equipo capaz de recoger, analizar y transmitir, es decir, las mismas funciones documentales que se llevan a cabo en un centro de documentación, pero además no hemos de olvidar el último eslabón, la pantalla en la que se recibe y que cierra el ciclo técnico.

Un grupo de investigadores y profesores de la Universidad Autónoma de Barcelona, encabezados por María José Recoder, ${ }^{16}$ han sido pioneros en el estudio de estos conceptos y se han centrado no sólo en la información electrónica, sino en los servicios que se ofrecen. Para ellos, el término información electrónica se refiere:

\section{A todos aquellos sistemas o servicios de información en los cuales ésta se almacena y distribuye a través de un soporte magnético u óptico y que, por tanto, puede ser leída por ordenador.}

Estos investigadores le confieren un matiz especial al empleo del adjetivo electrónico, puesto que permite diferenciarlo del concepto clásico en el que se movían los documentos hasta entonces; es decir, el papel, y lo actualizan hasta presentarlo en su nuevo soporte, bien magnético, bien óptico, lo que documentalmente incide de forma importante, sobre todo si consideramos que las memorias de almacenamiento se han ampliado hasta límites nunca antes considerados.

Si esta forma de presentar la información influyó en un mejor producto informativo en los periódicos, para el centro de documentación supuso un sistemanuevo de trabajo y otras maneras de colaborar con la redacción, ya que los servicios que envía el documentalista tienen ahora más importancia, porque éste se ayuda de las nuevas tecnologías para recuperar cuanto antes unainformación y ponerla a disposición del redactor.

\section{SOPORTES EN LOS QUE CIRCULA LA INFORMACIÓN ELECTRÓNICA}

La llegada de la información en línea a las redacciones y a los centros de documentación planteó un nuevo sistema de trabajo y, sobre todo, de adaptación a los nuevos soportes, lo que implicó un cambio en la forma de trabajar en ambos. En apenas diez años se han ido imponiendo nuevos soportes en los que circula la información, desde el periódico por fax hasta el periódico personalizado; pero tenemos que ser más exhaustivos en este campo y conocer todas las posibilidades que ofrecen los servicios electrónicos antes de determinar cuáles serán las funciones del documentalista, que está ahora influido por nuevos soportes que almacenan más información y la recuperan de manera más rápida.

Los primeros servicios con los que trabajaron los centros de documentación de los periódicos y también de las diferentes empresas fueron las bases de datos en lí-

16 María José Recoder Seellarés; Ernest A badal, Lluís Codina: Infomacón detrónicaynuevastemdogas Barcelona: PPU, 1991, p. 17. 
nea, si bien inicialmente las bases de datos surgieron en el ámbito científico y como tal sirvieron a la comunidad científica. Su ampliación a otros campos surgió de su propia estructura, ya que al producirse la explosión de la información, la necesidad de seleccionar y resumir obligó a los documentalistas a concentrar la información y hacerla más accesible.

Si anteriormente sosteníamos que eran los Estados Unidos quienes habían impulsado Internet, su experiencia previa había sido determinada por un hecho más o menos similar, ya que este gobierno subvencionó las investigaciones y los trabajos que fueron necesarios para constituir las bases de datos. Muchas de las que entonces se crearon - Medline, Dialog, BRS- aún siguen vigentes y hasta han aprovechado parte de su producto para colocarlo - venderlo- en Internet:

La primera utilización de los ordenadores para la búsqueda bibliográfica tuvo lugar en los EUA en 1954, y se mantuvo en el ámbito experimental durante más de una década... En los años 70 se producen avances tecnológicos importantes en el campo de las telecomunicaciones: aparecen las primeras redes digitales de transmisión de datos. ${ }^{17}$

Si dejamos de lado la información científica que suministran las bases de datos y nos centramos en el campo de la comunicación, ${ }^{18}$, hasta entrada la década de los setenta no aparecen los productores de bases de datos con un carácter eminentemente informativo, tales como el Infomation Bank, del NewYork Tims que se creó como servicio de venta de información, y que posteriormente fue utilizado por los redactores del periódico, o el DowjonesNens Rerieval. Estas primeras bases de datos ofrecen resúmenes de prensa en diversos campos temáticos, algunos obtenidos del propio periódico o del resto de ediciones importantes del país en el que trabajan.

A partir de estos proyectos, los productores de información vieron un negocio en la información electrónica, aunque antes tenían una ardua tarea por desarrollar, para estructurar, preparar, elaborar, resumir o dar completala información que el usuario requería. D e esta forma, el trabajo del documentalista aumenta, pero la información consigue retos hasta entonces no alcanzados al permitir contrastar de forma inmediata, o en escasos minutos, un dato, un punto de vista, un planteamiento diferente que no queda suficientemente claro.

El problema radica en el precio que hay que pagar. A los periódicos importantes, aquellos que quieren acaparar más mercado, no les importa pagar ese servicio, si a cambio sus redactores consiguen lainformación puntual y contrastada que requiere su trabajo. Pero no siempre hay que pagar, pues algunos productores de bases de datos son los organismos e instituciones de un país y las crean para difundir la cultura, por lo quetambién pueden ser usadas por los centros de documentación delos periódicos.

17 María José Recoder Sellares; Ernest Abadal, LLuís Codina: Infomaaón detrónica... Op Cit, p 52

18 No hemos de olvidar que también las bases de datos científicas han sido un apoyo importante en la elaboración de tareas informativas. 
Al mismo tiempo que productores, algunos son también distribuidores, es decir, se encargan de crear y vender la información, e incluso facilitan todos los soportes técnicos y el sattwarenecesarios. Los distribuidores o hostlos podemos definir como aquellas empresas quetienen en su poder grandes ordenadores - mainframes- en los que se selecciona, analiza y almacena una gran cantidad de información, que luego se envía a los usuarios previo pago de una tarifa anual o por servicios individuales. En todo caso, no hemos de olvidar los lenguajes que emplean estos host, que han de ser coincidentes con los que utiliza el usuario ni que éste disponga de una terminal remota, con modem incluido, para recibir el producto informativo. Los usuarios pueden recibir el resultado de sus consultas, en papel, en línea y a su vez sacarlo mediante la impresora o en CD-ROM.

Si bien fueron importantes los servicios que las bases de datos le facilitaban al periódico, mucho más lo fueron los de teletexto, ya que éstos terminaron formando parte del producto informativo propiamente dicho y hoy, en España, el mayor porcentaje de los servicios de teletexto se sustenta en lainformación. El videotexto, tanto el interactivo como el de difusión, tiene como materia primala información, pero no ha pasado de ser un servicio muy simpley apenas consultado, por lo que ha desaparecido o se ha dejado comer el terreno por Internet.

D entro de este análisis de los soportes en los que circula la información electrónica hemos de dar un salto en el tiempo. Así, mientras los soportes en línea seguían ofreciendo información, el avance tecnológico lograba aumentar la capacidad de memoria de los soportes y desbancaba a los magnéticos para dar paso a los ópticos. Los discos ópticos eran tan manejables como el papel, tenían una gran capacidad para almacenar datos, eran muy resistentesy so bre to do interactivos: podía buscarse la misma información en todo el disco con una sola referencia. A propósito de lainteractividad, que tan importante es en nuestro planteamiento y desarrollo de la información electrónica, en el libro Infomación detrónicaynuevasteendogás de María José Recoder y o tros autores, se hace hincapié en las posibilidades actuales de diálogo entre la máquina y quien la maneja; de ahí el planteamiento de ofrecer un periódico personal en el que participan de forma activa y en tiempo real diferentes personas:

En cuanto a la interactividad, recordemos que esta denominación se refiere al atributo de aquellos sistemas de información que proporcionan respuestas rápidas y seleccionables por el usuario final, a través de un diálogo donde la máquinay el operario humano intercambian continuamente los roles de emisor/ receptor. A estos sistemas se les puede llamar también conversacionales. ${ }^{19}$

La respuesta parece estar en un producto interactivo en el que participen el redactor, los lectores y el documentalista intercambiando información y diferentes puntos de vista, y en que lo hagan de forma continua y no sólo pensando en una única edición, cada veinticuatro horas. La interactividad va a permitir modificar las informaciones cada vez que se produzca algún acontecimiento nuevo, de tal manera que

19 María José Recoder Sellares; Emest Abadal, LLuís Codina: Infomaaón deetrónica... Op Cit, p. 63 
de unaúnica edición se pase a un número indeterminado, dependiendo de las necesidades informativas del momento, según considera Ruiz de Elvira:

Los diarios están a punto de perder su nombre... en Internet... periódico que se publica todoslos días para pasar a ser periódico que se publica a todas horas. Los lectores que buscan información, la materia prima de los diarios, son cada vez más exigentes y no les basta con enterarse de las noticias a toro pasado, sino que presionan para que los medios presentes en Internet les pongan en bandeja actualizaciones permanentes del acontecer diario... perdón, horario. ${ }^{20}$

La realidad es otra. En Europa, y España no es una excepción, durantelos primeros años de funcionamiento de los periódicos electrónicos, la única edición impresa se colocaba en la versión online; posteriormente, se ofrecieron resúmenes de actualización cada varias horas, pero está aún por darse el paso decisivo, ya empleado en algunos periódicos electrónicos de los Estados Unidos, en los que la actualización es más reciente, casi al mismo tiempo en que se van produciendo novedades informativas del acontecer que cuenta ese periódico, como si se tratara de una información en directo de la televisión o de la radio.

Así pues, antes de todo esto, las bases de datos en línea y los discos ópticos, principalmente CD-ROM y los discos compactos multimedia, han sido los soportes en los que ha circulado la información electrónica. Aún lo siguen siendo, pero la llegada de Internet ha modificado sus propios hábitos de trabajo, de tal forma que una parte de su información, a la que se puede acceder desde otros lugares, se sirve ahora de forma gratuita; el resto, se sigue cobrando, pero hasta los propios distribuidores se han dado cuenta de que el futuro es Internet u otro tipo de redes que se vayan creando, de tal forma que los productos se ofrecen en la Red, previa autorización de un passwardy una cuenta para cobrarlos.

\section{INCIDENCIA DE LOS NUEVOS SOPORTES EN EL CENTRO DE DOCUMENTACIÓN}

Las exigencias propias de la información obligaron a los editores de medios de comunicación a plantear la documentación como un servicio complementario de la información cuando se dieron cuenta de la importancia de presentarle al lector una información completa, o mejor dicho, con más datos quela información que aparecía en el periódico de la competencia.

Si bien los centros de documentación conocían los servicios que se podrían conseguir en línea, los documentalistas que trabajaban en los periódicos no habían experimentado los lenguajes con los que se habían creado esos servicios. Fue necesario, por tanto, un proceso de adaptación antes de llegar a la información y prepararla para ser enviadaa la redacción. Además, en los primeros centros de documentación,

20 Mariló Ruiz Elvira: "Enpugna conlosdianios WorddMedia Network". En: El País, 18 de diciembre de 1997, p. 52 
las fuentes con las que primero se trabajaba eran las propias del medio, es decir, los recortes de las informaciones que aparecían en el periódico.

Con la llegada de los ordenadores a la redacción y, posteriormente al centro de documentación, los documentalistas empezaron a replantearse el trabajo de selección, análisis, clasificación y recuperación de la información. Había que estudiar las diferentes necesidades de la redacción para luego acertar con las peticiones que hicieran los redactores. En la mayor parte de los centros, la solución inmediata fue aprovechar los textos y las imágenes, ya digitalizadas, para con ellas hacer una base de datos y así poder contar con la producción propia. Si no se obtenía la información pertinente se comenzaba una búsqueda de información en línea, preferentemente alguna base de datos temática o biográfica, dependiendo de las necesidades de cada redactor.

Como la información propia crecía al mismo tiempo que iban aumentando el número de páginas y el número de suplementos, el centro de documentación se veía impotente para aplicarle a todos los documentos el proceso documental. Se pensó entonces en gestionar, de manera propia o a través dealguna empresa, un porcentaje de los documentos que se recibían en el centro, sobre todo porque la información electrónica permitía un almacenamiento muy superior si estaba tratada, que aquél que permiten las viejas tecnologías del papel.

La creación de un Sistema de G estión Electrónica de D ocumentos (SGED) fue una solución que le permitió al centro de documentación periodística ordenar y recuperar la información electrónica. Uno de los métodos más empleados fue la presencia de los WORMen el centro, con lo que se sabía dónde estaba la información y cómo conseguirla cuanto antes:

La idea básica consiste en evitar la manipulación del papel y almacenar, recuperary reproducirlainformación de una manera totalmente automatizada desde una estación de trabajo electrónica, que utiliza discos ópticos como almacenamiento masivo. ${ }^{21}$

Con el paso del tiempo y aproximándonos más al momento actual -si bien estos discos se siguen utilizando- lo importante para el centro de documentación es que en los periódicos toda lainformación (gráficos, fotos, iconos, etcétera). se digitaliza, con lo que se puede guardar tal y como se ha confeccionado, sobre todo en aquellos en los que sólo se emplea para uso interno del periódico. Incluso, la información electrónica les permite a los documentalistas recuperar las páginas enteras del periódico y a partir de ahí guardarlas como una unidad, o bien confeccionar una base de datos temática que indique las referencias del día en que se publicó el periódico.

Éste sí se puede considerar un paso decisivo para la documentación. Si el periodismo seaprovechade las tecnologías para elaborar lainformación de manera más rápida yveraz, el centro de documentación sigue su estela al desechar los tradicionales so bres en los que se introducían los recortes para luego recuperarlos. Eso forma ya parte de la historia, pues no sólo el texto sino también la imagen se pueden almacenar tal y

21 María José Recoder Sellarés; Emest Abadal, Lluís Codina: Infomaaón detrónica.. Op Cit, p. 73 
como llegan desde la redacción. El centro de documentación ahorra espacio y tiempo, que se puede emplear en otros servicios como el de búsqueda y colaboración de los temas tratados a diario y que han de formar parte del número que se editará el día siguiente.

Existe una labor documental puntual en los periódicos, que consiste en resolver las pequeñas dudas que se producen mientras se elabora la información y que antes tenían como punto de contacto las obras de referencia, mientras que con la llegada de la información electrónica, la solución pasa por consultar cualquier CD -RO M que trate de esos temas y en apenas unos segundos se sabrá la respuesta. A provechando estas ventajas otras funciones del centro serán la preparación de temas concretos y puntuales, que aunque no tienen la urgencia del día a día terminan siendo igualmente necesarios para la elaboración de cualquier reportaje 0 entrevista.

Entonces, ¿de qué forma incide la información electrónica en el centro de documentación de los medios de comunicación? Facilitando los resultados de la búsqueda con suficiente antelación como para que el redactor no tenga que estar esperando. Además, el redactor puede recibir en su propia pantalla las referencias, sin tener que desplazarse e, incluso, puede acceder directamente a una parte del trabajo documental si considera que él puede profundizar mejor en los conceptos cuando se trate de documentos completos.

Hay otro campo en el quela documentación ha aprovechado lainformación electrónica. Nos estamos refiriendo a aquellos servicios que presta el centro a usuarios ajenos a la empresa y que en algunos casos constituyen una buena fuente de ingresos. En este sentido, todas las informaciones requieren un trabajo posterior para que cuando el usuario las solicite le sean servidas. Laventaja que tiene el centro es quelas informaciones generadas por sus propios periodistas ya no tienen que ser tratadas, puesto que el servicio hace referencia a datos periodísticos ya hechos noticiosos que ya están contenidos en la propia información. Aun así, casi ningún medio de comunicación se conforma con guardar las informaciones que publica de forma íntegra, aunque sí lo hacen como recurso de hemeroteca, y de hecho algunos periódicos editan dos o tres CD-ROM al año con la información completa.

Hay un trabajo complementario, de análisis documental, de indización o de resumen documental que es hecho por los centros de documentación periodística para que cuando haya que buscar referencias, la pertinencia de la búsqueda sea mayor. Así, se confeccionan bases de datos temáticas, onomásticas, geográficas, etcétera. Incluso en algunos casos se coloca como referencia la información de otros medios mediante un descriptor temporal que puede ser la fecha de publicación.

Es un salto cualitativo importante el que le aporta la información electrónica al centro de documentación, ya que el proceso documental se acorta y, lo que es más importante, la recuperación es siempre mucho más rápida y exhaustiva. La información electrónica no entró a formar parte dentro de la redacción y del centro de documentación hasta la llegada de los periódicos electrónicos, que utilizando las mismas herramientas permitían una interconexión de la información entre el redactor y el 
lector, o entre el redactor y el documentalista. Todo ello ha desembocado en la información especializada.

\section{INFORMACIÓN Y DOCUMENTACIÓN ESPECIALIZADA}

Las posibilidades que la información en línea les ofrecían a los medios de comunicación escritos pronto se vieron ampliadas en lo que se refiere a su contenido. D urante muchos años la voz llegó por teléfono a las redacciones de los periódicos; posteriormente la fotografía por satélite vino a demostrar quela información era tratada cada vez con más elementos, lo que implicaba una mejor calidad visual y un mayor enriquecimiento informativo. La información electrónica dio el paso definitivo al aportar todos los elementos que permitían un tratamiento diferente del producto informativo. Ahora, los periódicos tenían una lucha particular: completar de forma práctica la abundante información que recibían.

Con todos esos elementos la especialización era y sigue siendo, como se está demostrando en la práctica diaria, el requerimiento que los lectores demandaban. Así se lega a un proceso mediante el cual el redactor recibe una gran cantidad de información que, junto a la que él ha recabado, puede plasmar en una noticia muy elaborada. Ya no podemos hablar sólo de información electrónica recibida por diversos canales, sino del tratamiento que desemboca en una especialización queantes era impensable.

D e esta manera, tenemos que concretar las nuevas formas de tratar la información que luego se convertirá en personalizada, cuando lector y redactor puedan compartir los mismos elementos informativos y cada cual crear su propio contenido dependiendo del medio para el que trabajen: una gran empresa o un periódico personalizado.

En este ambiente, la documentación aprovecha también la llegadaal centro de información en línea, además dela generada por los propios redactoresy queya tieneun tratamiento digitalizado. El documentalista trabaja la información electrónica22 - D ocumentalista de Información Electrónica (DIE)- para contribuir a que la información especializada llegue al lector de forma más completa y veraz, con lo que tiene que adaptarse al ritmo que impone la llegada de la misma. Mientras tanto, lo mismo podríamos decir del periodista que trabaja la información electrónica - periodista de información electrónica(PIE)-, ya que aprovechando los continuos flujos informativos utiliza aquellos que tienen que ver más con su área de conocimiento - especializaciónpara ofrecer al lector una visión más completa y profunda de la información.

No será de extrañar, que andado el camino, ya más cerca de la meta que del inicio, ambas funciones se sobrepongan o, mejor dicho, se complementen, con lo que aparecerála figura de un nuevo comunicador, que recogerá lo mejor del periodistay lo más

22 Juan Carlos Marcos Recio: "El documentalista de información electrónica”. En: Doumentaciónde lasCieniasdela Infomadón Facultad de Ciencias de la Información. D epartamento de Biblioteconomía y D ocumentación, № 19. 
acertado del documentalista, para elaborar una información concreta, casi ala medida de lo que el lector-usuario demanda, y que no es otra cosa que la información especializada. Se da por seguro, porque así se está demostrando ya en la práctica, que el lector pasa a ser una persona que interviene en el proceso informativo en el tema en el que es un especialista y que no se conforma sólo con leer lo que los periodistas crean. Hay, por tanto, una simbiosis de la comunicación en la que el flujo informativo fluye con más velocidad y en la que los contenidos informativos se multiplican.

\section{INFORMACIÓN ESPECIALIZADA: APOYO FUNDAMENTAL DE LA DOCUMENTACIÓN}

El trabajo del documentalista sufrirá en breve algunas pequeñas adaptaciones que le serán impuestas por la velocidad con la que circula la información y por las exigencias de los usuarios, que ahora tienen ya opciones de elección y que en muchos casos sólo estarán dispuestos a pagar por aquella que les interesay que al resto de lectores no les sirve para nada. Hay que centrarse, por tanto, en una información especializada o, mejor dicho, única y al servicio de quien la paga, como señala Trejo:

Los usuarios - gracias a las redes de fibra óptica- tienen la posibilidad (aunque no siempre la aprovechen) de ser algo más que receptores de toneladas (o si se quiere gigabytes) de información. Pueden responder, reaccionar, interactuar. En otras palabras: la posibilidad para que los usuarios del ciberespacio sean actores y no sólo espectadores delos mensajes que se les presentan, está directamente ligada a la velocidad con que se conectan en las redes. ${ }^{23}$

Este es precisamente el aspecto que queremos resaltar. Lainformación especializada es el paso previo a la información personalizada, en la que el usuario-lector elige aquellos contenidos que más le interesan y trabaja sobre ellos con la posibilidad de interactuar o de cambiarlos con otras personas, en lo que podría ser un periódico personalizado, si esa información se presenta bajo un prisma periodístico.

En este sentido tenemos que pensar que la información electrónica, en general, no es un punto de referencia sobre el que se va a trabajar en el próximo siglo. Al contrario, será la materia prima con la que las instituciones públicas y privadas actúen y, cómo no, los editores de los periódicos que ya la utilizan desde que el producto periódico descubrió su valor.

Todo este avance viene apoyado en las nuevas tecnologías, de tal forma que el valor de la información se incrementa no sólo en una primera fase que tiene que ver con su conocimiento -informativo- , sino en una segunda, cuando actúa como punto de respuesta con el usuario a través de unainteractividad. El fruto de esa simbiosis entre tecnología e información es un nuevo producto que llega y se puede volver a enviar con respuesta. Es entonces cuando el documentalista ha de intervenir para ofrecer los apoyos documentales precisos en los dos momentos de la información;

23 Raúl Trejo D elarbre: Lanueaalfonbramágica: UsosymitosdeInteme Madrid: Fundesco, 1996, p. 41. 
en el previo, como lo venía haciendo hasta ahora, pero apoyado en las nuevas tecnologías; y en un segundo momento, para ayudar y ampliar la respuesta, si es que el usuario no ha sido capaz de cosechar los apoyos precisos, algo impensable, de momento, en este mundo y en sus volúmenes de información.

El usuario-lector podrá rescatar textos del periódico para trabajos futuros, con lo que realizará también una labor documental, algo que podrá hacer en unos cuantos segundos. El problema central de lainformación especializada consiste en saber qué le puede interesar más al lector, si un contenido cargado de reflexión tal y como han venido haciendo los periódicos a lo largo de su existencia, o la actualidad-instantaneidad que permiten los periódicos en línea.

Hemos de considerar que, aunque disponemos de información fácil, tenemos que pagarla. Una cuestión es que técnicamente podamos recibir la información en casa en lugar de bajar a la calle cuando nieva a comprar el periódico, y otra el precio que hay que pagar por ese servicio. Además, no siempre sabemos valorar los costos con el resultado final de las búsquedas, y aquí tenemos un ejemplo claro con los servicios de información en línea y las consultas a bases de datos, donde a pesar de precisar la pregunta al máximo, algunas veces se paga por más información de la que realmente usamos para nuestro trabajo o investigación.

Por otra parte, como puede comprobar cualquiera que se acerque a consultar no sólo estos servicios en línea sino en la propia Internet, la cantidad de información es tan grande que casi nunca conseguimos obtener today, lo que puede resultar interesante como documentalistas es tener de esa selección alguna parte importante de la información. D e ahí que no baste con llegar a la fuente de información. Luego hay que acertar en la selección, comprenderlay prepararla para que sea usada; por eso no todos parecen estar de acuerdo en su defensa, entre ellos Mark Slouka:

Mi molestia con la revolución digital, para decirlo llanamente, es que ofrece demasiado poco y exige mucho. Lo que ofrece es información, montones y montones de información y una nueva, abstracta suerte de 'enlazamiento'. Lo que pide a cambio es que modifiquemos nuestra lealtad, del mundo físico, al virtual. Es un mal trato, no sólo porque ignora nuestras necesidades biológicas, sino porquelimita nuestra autonomía. ${ }^{24}$

Por tanto, el conocimiento técnico einformático no es una garantía para elaborar y seleccionar información. Hay que contar con una base documental para discriminar aquellas partes que no van a ser necesarias y ofrecer el apoyo que el redactor 0 que el usuario demanda. La tarea esencial de la documentación será un trabajo serio y riguroso que permita completar una información de actualidad, a la que le aportará datos importantes y, en segundo lugar, una actualización constante delos diferentes aspectos que genere esa información para reutilizarla en otras ocasiones, una vez que haya sido realizada la selección oportuna, así como su análisis.

24 Mark Slouka: War ofthewords Cybaspaceandtheligh-techassaultonreality. Basic, Harper-Collins, Nueva York, 1995, p. 147. 


\section{EL DOCUMENTALISTA DE INFORMACIÓN ELECTRÓNICA (DIE)}

Es evidente que para la actualización de las noticias se ha de contar con un buen centro de documentación, en el que ahora tiene cabida una nueva figura: el D ocumentalista de Información Electrónica (D IE ), con amplios conocimientos en varias ciencias, fundamentalmente la informática y la lingüística, y un gran desenvolvimiento en bases de datos y búsqueda y recuperación de la información.

Estas funciones, hasta ahora realizadas tradicionalmente, toman un nuevo valor, y hay que pensarlas con otra mentalidad. No se trata de ofrecer el último dato de una obra de referencia, que en escasos segundos se consigue consultando cualquier enciclopedia electrónica, ahora el D ocumentalista de Información Electrónica participa plenamente de los contenidos de la información; ya no se queda al margen, es parte del contenido de la noticia, todo lo cual desemboca en un nuevo documento al que el documentalista llega con amplios conocimientos.

El origen del DIE lo podemos encuadrar en los trabajos que se hicieron en las primeras bases de datos. La información era entonces amplia y había que tratarla de forma adecuada para que la recuperación no fuera una pérdida de tiempo. Se establecieron entonces criterios de eficacia y la documentación pasó a tener una consideración casi decisiva en cualquier proceso de creación de ideas, no sólo de carácter científico sino también periodístico.

La llegada de la información electrónica a las redacciones y su presencia en los centros de documentación, ya tratada y digitalizada, aceleró el proceso documental de tal forma que con la mitad de documentalistas se controlaba y se preparaba el contenido, que pasaba luego al fondo documental para posteriores recuperaciones. El tiempo ahorrado se empleaba en otros servicios. De esta forma, podemos considerar al D IE como una persona que debe disponer del tiempo necesario para autoevaluar los contenidos informativos que llegan al centro. Ahorano es preciso trabajar al ritmo que imponen las noticias, sino al que marca el centro.

Es, por tanto, la propia información electrónica la que obliga a cambiar el planteamiento de trabajo en el centro de documentación, donde ya no importa tanto el dato puntual, pues se han diseñado bases de datos tan sencillas que el propio periodistapuede confirmar si el dato es correcto o no, y en un tiempo pequeño; ahora hace falta que además se incluyan textos más amplios. Este documentalista se aprovecha de las nuevas tecnologías para ir equiparando el centro de documentación a la redacción.

Una investigación llevada a cabo en algunos periódicos españoles nos permitió acercarnos a una realidad - constatada en unos cuantos, pero con una proyección futura inmediata-, en la cual la documentación se pone a la altura de la información. Por tanto, ya no va por detrás de lainformación, ni tampoco por delante, puesto que es imposible conocer el hecho noticioso antes de que se produzca, aunque aquí hay excepciones que desde el centro de documentación se han salvado convenientemente-nos referimos a un trabajo puntual que elaboran los centros de documentación periodística y las propias redacciones, que tiene que ver con la vida de personas 
ilustres que ya tienen confeccionada una biografía para que en caso de fallecimiento se pueda realizar una tirada de ejemplares lo antes posible- . A partir de ahora, el centro de documentación se pone al lado de la redacción y participa también del proceso noticioso.

Si estamos analizando la figura de un nuevo documentalista es porque las tecnologías obligan a los integrantes del centro de documentación a ampliar su radio de trabajo. Volvamos la vista atrás, no más allá de veinte años, y nos daremos cuenta de que en apenas un cuarto de siglo la documentación en general ha sufrido una transformación importante, pero más si nos referimos alos medios de comunicación, sobre todo los audiovisuales, donde el tratamiento de la imagen hizo que se dieran nuevas pautas de análisis para poder recuperar las imágenes a tiempo y, desde hace un par de años en los medios escritos, donde el nuevo concepto de periodismo hace que el documentalista participe de otra forma de la información.

En efecto, atrás han quedado los sobres en los que se encerraban fotografías y grabados sin ningún criterio, excepto el alfabético, para luego recuperarlas. Pero si analizamos el contenido de lo que en aquellos sobres había, nos daremos cuenta de que era casi imposible saber adónde se queríallegar. En el caso de los textos, lo máximo que podíamos encontrar era alguna frase subrayada que quizás le podía interesar quizás a quien hizo esa tarea documental -si es que eso se puede considerar documentación- . Claro que había una forma de acertar siempre: subrayar temas generales, ideas muy extendidas entre los diferentes pensadores 0 aspectos concretos que geográficamente podían interesar al resto de redactores. Porque no olvidemos que eran los propios periodistas quienes se encargaban del archivo, que en algunos medios se hacía por secciones y que en otros era una persona, a punto de jubilarse, 0 aquella que no tenía una ocupación fija, la que se encargaba del centro de documentación - mejor dicho del archivo.

Y si hablamos de la imagen fija la situación era mucho peor, las fotos se recortaban y se metían en so bres que posteriormente se almacenaban por temas generales y dentro de cada so bre por aspectos más puntuales. Para hacer una consulta, el redactor miraba en una lista colocada en la pared la relación de temas o colores y el número que se le había adjudicado a cada sobre. Sucedía, a menudo, que los grandes temas, como Estados Unidos o Europa, ocupaban varios sobres, con lo que muchas veces se perdía uno en una búsqueda o terminaba cambiando de tema. No era extraño que en aquellos tiempos se variara con suma facilidad la maquetación de una página por no encontrar el apoyo gráfico requerido para esa información. Así, lo que iba a ser una noticia importante dentro del contexto de la página se quedaba en un suelto o una columna, con lo que la valoración informativa no era la requerida ni la que esperaba el lector.

Por otra parte, estaban las fotografías de producción propia, es decir, aquellas que habían sido hechas por los fotógrafos del periódico. D ependiendo del tema, las fotografías publicadas se dejaban durante unos días en la mesa del redactor jefe, por si era necesario continuar; el resto se iba almacenando en un montón hasta que alguien 
decidía meterlas en un sobre. Los encargados de realizar las fotografías eran también, por su propio interés, quienes las controlaban, pues en algunas ocasiones les resultaba más fácil y rápido recuperar una fotografía de un monumento importante de la ciudad, que ir de nuevo a hacerla.

En ningún caso, ni con el texto, ni con la imagen, el centro de documentación o archivo tenía el contenido que la información exigía. Era una forma de trabajar que resultó rentable para las empresas de prensa porque el gasto en personal era nulo, pues como hemos constatado eran los propios redactores y fotógrafos quienes se encargaban de ambos trabajos.

¿Qué obligó a las empresas a cambiar? ¿Cuándo deciden que la documentación periodística tiene valor? ¿Q ué criterios se emplean a partir de entonces? ¿Quién es pionero en este trabajo?

Se pueden buscar respuestas de toda índole a estos planteamientos, pero la que más se aproxima es aquella que tiene que ver con un hecho social: es la propia sociedad la que va aceptando los periódicos que están mejor documentados, frente a aquellos que siguen con los métodos tradicionales. Hasta entonces, la información no era competencia, los periódicos constataban una realidad y lo hacían desde sus puntos de vista editoriales, que era lo que los diferenciaba del resto.

La llegada de la democracia y la aparición de nuevos periódicos, en el caso español, vino a constatar un hecho que antes no había resaltado nadie: el centro de documentación. Así, El País decidió dotar a su centro de importantes medios para que sus redactores completaran las noticias tal y como la nueva sociedad demandaba. Y otros muchos periódicos de tirada nacional hicieron lo mismo.

Las empresas entran en una lucha por captar nuevos lectores. Hasta entonces, parecía que había un consentimiento generalizado y cada periódico tenía los suyos, sin intentar competir, aunque hubiera pérdidas que se salvaban muchas veces con las ayudas estatales. A partir de estas fechas, el concepto de documentación cambia porque la sociedad lo exige, pero también porque algunas empresas deciden apostar fuerte por una información completa, en la cual ya no sólo participa el redactor sino también el documentalistay, naturalmente el experto, que aporta su punto de vista siguiendo un esquema informativo y no, como se había hecho hasta entonces, mediante un artículo de opinión.

La documentación pasa a primer plano, aunque no en todos los medios, ni siquiera en los más importantes. Pero se da el paso definitivo cuando los lectores empiezan a apostar por los nuevos periódicos que presentaban las noticias con diversas opciones y con una carga documental importante. Fue entonces cuando se decidió incluir otros contenidos en la información. Es así como el ahora centro de documentación comienza a recibir numerosas peticiones de todas las secciones del periódico que van necesitando datos para hacer una información veraz, objetiva y completa.

También sufre el centro de documentación un cambio importante. Ya no hay una persona que se encarga de hacer un poco de todo, ahora hay un equipo humano que tiene conocimientos previos sobre cómo tratar la información e ideas claras en 
torno al proceso de seleccionar la información, de analizarla y de tenerla lista para cuando se vuelva a necesitar.

En teoría, para los periódicos españoles que entonces empezaron fue fácil poner en orden el centro de documentación. Se trataba de no ir acumulando las noticias sino de irvalorando cadauna de ellas y dejándolas organizadas para su recuperación. El problema lo tenían aquellos medios que ya contaban con un material importante acumulado al que no le habían buscado ninguna solución. Hubo medios de comunicación que decidieron hacer una cuidadosa selección, quedarse con muy pocos documentos y desechar el resto, mientras que o tros intentaron aprovechar todo el material y terminaron perdiendo eficacia.

En ambos casos - periódicos nuevos y ya constituidos- el problema no se solucionó hasta la llegada de las nuevas tecnologías y no del todo, puesto quelainformación es siempre mayor y va delante de la documentación. Además, cada vez que una noticia se somete a análisis documental puede generar un nuevo documento, en este caso secundario, con lo que la información amplía aún más sus límites.

En veinte años hemos pasado de la acumulación sin un orden claro y sin unas funciones concretas en el centro de documentación, a un tratamiento documental de la información. Pero este tratamiento se ha visto desbordado por la presencia constante de información. Y a no estamos hablando de la explosióndelainformación en el sentido de que es tanta que es imposible controlarla, nos estamos refiriendo a las posibilidades que eso ha permitido. La llegada de la información a muchos lectores ha originado un nuevo proceso en el queel lector está preparado para participary del que quiere ser parte, porque ya no se considera un lector pasivo sino una persona con conocimientos y con ideas que pueden interesar al resto de los lectores.

Hemos llegado a un momento en que la información está en constante movimiento. No podemos pensar ya que el lector es conformista, que quiere una noticia con los contenidos informativos precisos, como sucedía hace unos años. Ahora el lector se siente parte de la misma noticia y con la fuerza suficiente como para dar su propia versión de los hechos.

Si además las nuevas tecnologías permiten recoger todas esas opiniones, lo ideal sería que el periódico que resulte de todo este proceso sea también parte del lector, no sólo del centro de documentación que ha ofrecido diversos aspectos de la noticia, ni del redactor que ha contado todo aquello que ha visto o que otros han visto por él. A hora es el momento de convertir al lector en protagonista de las historias que le son próximas y que domina. Estamos refiriéndonos, una vez más, al periodismo personalizado, que crea el Diario Yo o Periódico Personal.

Este paso, previo al nuevo concepto de documentación que proponemos, tiene que ver con una actitud que las empresas de comunicación valoran muy escasamente. Sólo cuando el lector pasa por el lugar de la noticia es cuando está autorizado a colaborar y siempre mediante el trabajo de un redactor, lo que mediatiza la información.

Pero no hemos de olvidar que la documentación tiene un carácter de formación en el usuario, a quien le aportanuevos conocimientos. D esde este punto de vista he- 
mos de considerar el nuevo trabajo de la documentación, en el que el lector se siente protagonista de la información y está dispuesto a crear su propio periódico, - el periódico yo o periódico personalizado- para hacer llegar sus puntos de vista a otros lectores. Si, además, técnicamente esto es posible y sin un alto costo, hemos de considerar que los periódicos le deben mayor respeto a sus lectores y sobre todo una mayor participación, si no quieren perderlos como lectores.

A quí entra en funcionamiento el D ocumentalista de Información Electrónica para completar la formación necesaria que ha de tener el lector que desea datos e informaciones para elaborar su página dentro de un periódico personalizado por otra persona. El DIE no sólo trabaja como apoyo para que ese periódico tenga una información completa, sino para que la formación de sus lectores estéa la altura de sus necesidades. Es un servicio que el centro hace, pero no de forma gratuita sino cobrando una parte 0 intercambiando documentos con los miembros que hacen ese periódico.

Pero el D IE vive inmerso en el proceso informativo, de tal manera que ha de ofrecer sus contenidos al periódico en el que está enclavado. D e esta forma, los centros de documentación no ofrecerán sus contenidos a aquellos medios personales que les planteen competencias, por lo que éstos deberán pensar en otras formas de conseguir su apoyo documental.

Es en esta doble vertiente, para servicio propio del periódico y como fuente de ingresos para la empresa, donde el documentalista que trabaja con medios electrónicos habrá de desarrollar su principal actividad. La documentación deja de ser ese aspecto que a casi nadie le interesa para convertirse en una de las ideas claves del contenido noticioso con que el redactor está trabajando.

Hay otro aspecto documental que puede interesar en la confección de ese proceso de periódico personalizado y que ya se utiliza cuando se accede a la información que contienen las bases de datos. El documentalista que trabaja la información electrónica aprovecha estos soportes para concluir cuanto antes el proceso documental y dedicar más tiempo al trabajo propio que le exige el nuevo concepto de periódico, en el que participa con los datos que obtiene de su búsqueda documental y con una versión propia, obtenida de un resumen de las ideas con las que ha trabajado y que al final forman parte de la información que ha de ser publicada.

El documentalista se siente así parte de ese trabajo que antes no era considerado importante y que ahora, junto a los aspectos parciales de la noticia, puede incluir la apreciación de un hombre formado en el campo no sólo de la documentación sino también en el delainformación electrónica. Lo que se crea es una simbiosis deinformación y documentación, y consecuentemente la de quienes ejercen estas dos profesiones. Se pasa, por tanto, de una actividad de apoyo a una participación plena en la noticia, aunque sea el redactor quien tenga la última palabra y no siempre acepte los planteamientos del documentalista.

El futuro del DIE pasa por atender las necesidades de los periodistas que elaboren su propio periódico. Será un servicio decisivo en estos medios, ya que no tendrán infraestructura suficiente como para crear su propio centro. Estamos hablando 
El uso de la tecnología de la información entre investigadores mexicanos... 93

de periódicos cuya consulta al centro es fundamental para comenzar a redactar una noticia, porque ese periódico personalizado lo están haciendo y editando personas que en muchos casos ni siquiera son periodistas.

\section{FUNCIONES QUE DEBERÁ DESARROLLAR EL DOCUMENTALISTA DE INFOR- MACIÓN ELECTRÓNICA}

Si el documentalista ha de asumir parte del riesgo de la información, lo ético será que se le deje libertad para entrar en los temas contando su experienciay, sobre todo, resumiendo los datos delo que dicen los expertos en ese campo. Así, no todas las noticias llevarán su apartado documental, pues hay hechos que con sólo los datos precisos ya quedan cubiertos. Esto no quiere decir que cuando se implanten los periódicos personalizados no se pueda y deba documentar cada una de las noticias, pero la sociedad en la que nos movemos actualmente demanda una documentación exhaustiva.

Son muchas las actividades que tiene que desempeñar el DIE, pero hay una que es prioritaria: añadir una ayuda básica y amplia de los contenidos sobre los que trata la noticia con base en las necesidades de los lectores. Habrá lectores que recibirán el encargo de completar una información o modificar bajo sus criterios alguna otra ya publicada. Para ello necesitarán consultar el centro de documentación del periódico u otro que venda ese tipo de informaciones.

Ser partícipe de la noticia es colaborar en la confección de una parte de ella. No es fácil entregar algo que no se tiene. Por un lado, el documentalista ha conseguido una formación que le hace estar preparado para contar aspectos parciales, no todos de la mismaformay quizás mucho mejor queel propio periodista, pues no en vano el documentalista está acostumbrado a realizar resúmenes, lo que implica la extracción de una serie de ideas, siempre las más importantes y las que tienen que ver con el tema central del documento. Por otro, debe buscar todos los aspectos paralelos de la noticia para que el redactor nunca se sienta sólo a la hora de comenzar a redactar. Habrá casos, en que esos aspectos se conviertan en noticias con su firma particular: servicio de documentación, y otros en que el periodista se apropie del trabajo del documentalista.

Este reto de servicio sin límites es el mejor logro que habrá de conseguir el D IE, so bre todo porque las nuevas tecnologías le facilitan las búsquedas, ya que no el trabajo; pues una vez conseguidas miles y miles de referencias se inicia la ardua tarea de seleccionar, tratary ofrecer aquellas y sólo aquellas que el redactor está esperando.

0 tra de sus funciones es preparar aquel tipo de información que resulte más rentable para la empresa. Nos referimos, en concreto, a aquellos contenidos noticiosos que tienen que ver con la comunidad en la que está enclavado el centro, pues el D IE no ha de olvidar nunca el carácter local de las noticias, es decir la aproximación a las personas, pues tal ha sido la tradición, y ni siquiera las nuevas tecnologías (aunque tienen opciones para hacerlo) pueden romper el carácter social dela prensa. Sólo si cristalizara la existencia de una inmensa gama de periódicos personalizados se perdería ese 
sentido social que lleva aleer y conocer la misma realidad a una gran cantidad de personas, de lectores.

Pero el D IE tendrá que centrar su actividad en otro aspecto más difícil de conseguir para quienes pretenden ofrecer un servicio o información en formato periódico y de carácter personalizado. Nos referimos a la información que se generalejos, fuera del ámbito de movilidad en la que vive ese medio de comunicación y para el cual esa información es muy difícil de conseguir.

Hemos de ser conscientes que un periódico de estas características busca sobre todo lo más cercano a su ámbito y desarrollo social, pero no puede desechar aquellas informaciones que con el tiempo pueden influir en su forma de presentar las noticias. Además, el problema de conseguir información sobre fuentes lejanas a su área de influencia queda resuelto con las posibilidades que ofrecen sistemas como Internet, al grado que algunos teóricos de la comunicación piensan que en breve desaparecerán los corresponsales y sólo quedarán los enviados especiales que tengan alguna misión concreta para el periódico. No en vano, existe tal cantidad de información sobre algunos países que en cuanto se consigan ciertas cotas de actualización, la figura del corresponsal que trabaja resumiendo los periódicos y otros medios de comunicación del país habrá desaparecido, porque esos mismos datos se podrán conseguir en periódicos personalizados que tratan los diferentes temas que interesan a los lectores de un determinado país.

El DIE ha de desarrollar un método de trabajo que le permita no sólo entregar de manera rápida todas las informaciones que solicita la redacción, sino participar en el proceso de selección y, sobre todo, de análisis de las informaciones propias y aquellas quevan llegando desde otros servicios. Además, deberá establecer las pautas por las que se va a elaborar y entregar la información siguiendo el proceso documental que considera al redactor como el usuario que necesita esa información.

Este método de trabajo habrá de contar con un manual que contenga por escrito todas las indicaciones que debe cumplir todo integrante del centro de documentación. D e ahí que se exigirá un proceso de selección muy riguroso que no acapare documentos que luego no sirven o que apenas se consultarán: se trabajará teniendo en cuentalas últimas innovaciones quevayan produciendo los lenguajes documentales, para adecuar los procesos documentales a las necesidades del redactor y para que no se presenten pérdidas de información. Se estudiarán las necesidades de los redactores mediante diferentes encuestas, se compararán las informaciones que con más frecuencia se solicitan para enfocar hacia ese campo los trabajos documentales.

Es necesario que el D IE haga una autoevaluación de los resultados que va obteniendo el centro de documentación, tanto de los servicios que le son propios como de los que tienen como fin usuarios externos a la empresa. Esta evaluación no se hará únicamente para controlar el volumen documental y presentar la memoria anual de todas las actividades del centro, su función será la actualización constante que exige la información electrónica. 
Si hasta hace poco los centros de documentación llevaban a cabo un expurgo para eliminar aquellos documentos que ya no servían, en la actualidad las nuevas tecnologías pueden desechar aquellos que nunca han sido consultados, haciendo una selección previa, lo que facilita enormemente el trabajo posterior.

En cuanto a las herramientas que ha de utilizar el D IE, hemos de considerar que serán las mismas que emplea el documentalista para llevar a cabo su tarea documental, pero habrá que pensar que ya toda la información estará digitalizada, por lo que será necesario un gran conocimiento de los programas de gestión de documentos, de búsqueday almacenamiento en soportes ópticos y del desarrollo de los soportes en línea, de los cuales habrá de recuperar la mayor parte de los datos que no ha conseguido elaborar el propio centro.

\section{EL PERIODISTA DE INFORMACIÓN ELECTRÓNICA (PIE)}

O bservando el desarrollo de los diferentes medios de comunicación y lo que para ellos ha significado la presencia de un ordenador en sus redacciones, es fácil concluir que ha sido en la prensa donde más ha revolucionado el trabajo; no sólo en los talleres de composición sino en el trabajo diario de los propios redactores.

De pronto las viejas y gastadas máquinas de escribir, en las que alguna tecla ya fallaba, se vieron desplazadas a un rincón de la redacción. No fue así en todas las empresas de prensa, puesto que los primeros ordenadores no ofrecían la seguridad de los actuales y en algunas ocasiones se recurrió al viejo sistema. Sin embargo, los avances de la ciencia son imparables y así fue también con los periódicos. La presencia de los ordenadores, mejor dicho de un ordenador principal o minframe, que se encargaba de todas las operaciones y les permitía a los redactores jefes y subdirectores hacer las modificaciones que consideraran oportunas, significó una nueva redistribución, aunque para la mayoría de los periodistas eso supuso un desplazamiento, puesto que todo el proceso fue modificándose: el origen de la noticia, su elaboración, su redacción, su impresión e incluso su distribución.

Ningún cambio tecnológico llega de repente: hay una evolución, fundamentalmente social que va influyendo a las personas. Y no podemos olvidar que los periódicos viven de sus lectores, aunque en última instancia sea la publicidad la que salve el negocio editorial que supone un periódico. Además, los avances tecnológicos influyen de forma paralela en casi todos los campos del saber.

No hay que olvidar tampoco que el periódico está inmerso en una sociedad a la que orienta, pero de la que también se nutre para marcarle pautas. Una empresa de prensa debe conocer cuál es el índice de lectura de su zona antes de hacer una inversión en un periódico. Lo mismo sucede hoy en aquellas empresas que quieran conocer cuál será el índice de lectura de un periódico electrónico.

Primero habrá de determinarse el número de ordenadores, con su correspondiente software y hardware, para concretar después cuántos de éstos u o tros nuevos 
han llegado a los hogares, ya que una de nuestras propuestas es la creación de la información desde los propios domicilios, y luego deberá hacerse la recepción de la multitud de datos que serán proporcionados por centros de documentación especializados en atender a estos nuevos servidores.

Según datos de SEDISI (A sociación Española de Empresas de Tecnologías de la Información) hace quince años que en España se ha pasado de la llegada explosiva de los ordenadores a la madurez, con una crisis en medio que ha sido superada acertadamente para las empresas y los usuarios finales.

En los últimos quince años, el mercado informático español se ha multiplicado casi por siete veces, dato que es en sí mismo una buena representación del papel que este sector desempeña en el conjunto de la economía española. ${ }^{25}$

Lo importante es que algunos grupos de prensa española se dieron cuenta de esa situación hace tiempo, como explicaba el entonces consejero del G rupo Correo y hoy directivo de Tele5, Alejandro Echevarría, a finales dela década delos ochenta:

El periódico electrónico, su factura a medida del lector, el perfeccionamiento del marketing y la oferta especializada son, en cambio, hechos que ya definen el periodismo de los años noventa, en el que nos encontramos inevitablemente inmersos. ${ }^{26}$

Si bien algunas de las empresas más importantes de España ya lo han entendido así, ahora conviene dedicar un último esfuerzo para hacérselo comprender a sus trabajadores, desde la administración hasta la redacción y, sobre todo, a sus lectores. Pensemos que un economista está llevando desde su domicilio las cuentas de dos o tres grandes compañías, la mejor forma de estar informado, además de la radio y la televisión, será haciendo didk en la carpeta en la que se encuentre el periódico, que además aportarálas últimas novedades y lo nutriráconstantementedeinformación.

Es más, una vez realizado un perfil del usuario, o del lector, es técnicamente posible conocer mediante una señal luminosa o acústicala llegada de nueva información a su periódico electrónico, mientras que con el radio o la televisión hay que estar pendiente del momento en que llega el boletín horario. En los tres casos se exceptúa una información urgente que afecte a todos los usuarios de medios de comunicación, puesto que en ese caso se interrumpirá el programa que se esté emitiendo y se ofrecerá esa información. Al mismo tiempo que la sociedad española avanzaba, el periodismo se fue adaptando alas exigencias de los lectores así que el periodista tuvo también que ponerse a esa misma altura.

En una primera aproximación al Periodista de Información Electrónica (PIE) hemos de pensar que hasta la década de los noventa no podemos empezar a plantear este concepto dentro deuna redacción, aunque quizás años antes ya se realizaban in-

25 Sedisi, En: Computerwadd, XVI, p.16.

26 O fa Bezunartea: "La prensa ante el cambio del siglo". Bilbao: Editorial D eusto, 1988. En este prólogo Echeverría ya se muestra claramente a favor de seguir una línea nueva ante el reto que suponen las nuevas tecnologías. 
formaciones que podían encuadrarse dentro de lo que hoy entendemos por este tipo de periodismo.

Nos estamos refiriendo a la información electrónica preparada por el Periodista de Información Electrónica, que sería aquella que, previa determinación de su redactor jefe, elabora, prepara y envía el primero a la redacción desde lugares remotos y sin más intervención que sus propios conocimientos y lo que aporta el D ocumentalista de Información Electrónica.

Si nos detenemos un momento en esta definición, descubriremos que esta forma detrabajar hasido empleada por agencias de prensa hace ya tiempo, eincluso por algunos periódicos. Pero hemos de profundizar un poco más en algún aspecto de la misma. A principio de los noventa era común ya el uso del ordenador portátil entre algunos periodistas, quienes estaban obligados a enviar lainformación pocos minutos después de que finalizara el acto informativo. Era una información electrónica elaborada para un periódico que se imprimiría en papel, porlo que estábamos anteun periodista de información electrónica que lo único que hacía era aprovechar la técnica para no tener que grabar la información y que otra persona la pasase a la página.

Al mismo tiempo que la informática presentaba nuevos programas, los periodistas fueron adaptando su información. Así, antes de redactar su trabajo podían conocer cuál era la extensión de su crónica, si llevaba fotografía, si desde el centro de documentación añadían algo, etcétera. Al abrir su ordenador el periodista tenía la oportunidad de entrar directamente en la página en la que iba a plasmar su información e incluso podía escribir sobre la premaqueta, con lo que en la redacción apenas tenían que hacer modificaciones, lo que permitía un ahorro de tiempo. Sin darnos cuenta estábamos planteando una información electrónica realizada por unos cuantos periodistas situados en varios lugares donde se producía la noticia, y por una pequeña redacción que le daba los últimos retoques a la información. Podríamos decir que de esta manera, una parte cada vez más importante del trabajo se puede hacer fuera de la redacción si las empresas deciden apostar por este sistema.

Pero si el redactor encontró muchas facilidades fue gracias a la compaginación electrónica. Hasta la llegada de los ordenadores a la redacción, los textos se redactaban y se seleccionaban las fotos y los gráficos que luego se colocaban sobre una maqueta dependiendo del valor delas diferentes noticias. Se procedíaluego a anotar los originales y se llevaban al taller para que los picaran. Posteriormente se sacaban de la fotocomponedora los diferentes textos y las ilustraciones y se pegaban sobre la maqueta. Estos pasos se realizaban manualmente y con una considerable pérdida de tiempo y material si había que cambiar algún bloque o página por necesidades de actualidad. Afortunadamente el avance ha sido importante. En todo caso, cuando hablamos de compaginación electrónica debemos entender aquel proceso que permite reunir todos los elementos - texto, fotografía, gráficos, etcétera- que componen una página de forma ordenada y digitalizada para que la información pueda ser enviada y recuperada a través de una conexión online. 
Como un avance más lejano, aunque no irrealizable, las nuevas tecnologías de la información están ofreciendo la posibilidad de hacer periódicos sin periodistas. Es la redacción sin redactores algo aún impensable, pero que puede llegar en un futuro inmediato. En este sentido, las páginas se encuentran premaquetadas en los ficheros del periódico electrónico y cada lector, gracias a un passward podrá elegir una página o parte de ellay se hará responsable del contenido de la misma, con lo que casi todas las personas se podrán convertir en Periodistas de Información Electrónica, que necesitarán, en todo caso, de las tareas de asesoramiento y corrección de redactores, más habituados a trabajar en el campo de la información.

Pero el periódico tradicional tendrá que convivir durante algún tiempo con aquellos que se ofrecen en nuevos soportes. Los últimos años de este siglo serán intensos en las redacciones y así como en los años setenta y ochenta supusieron cambios significativos, otro tanto ocurrirá con el nuevo diseño de un periódico totalmente digitalizado, en su concepción, en su elaboración y en su reparto, como señala Fidler:

Inicialmente, las ediciones electrónicas diseñadas para pantalla electrónica serán complementarias de las ediciones impresas. Pero, para la mayoría de los editores de periódicos, revistas y otros productos impresos de carácter efímero, la mayor rentabilidad y las superiores cualidades de la tinta digital y de papel de silicio harán fácilmente irresistible la conversión total de esta forma de edición. ${ }^{27}$

Son, por tanto, las ediciones electrónicas las que mejor definen al periodista que emplea las nuevas tecnologías. Mientras no se separe el concepto de impresión en papel frente al de impresión inmediata en pantalla con una actualización constante, se le exigirá al redactor una especialización casi monotemática; entonces, no podremos afirmar que el Periodista de Información Electrónica está cumpliendo sus objetivos. Tiene tareas que cumplir, pero éstas no sólo estarán en sus manos, sino en las de las empresas que decidan apostar por un periódico en línea, actualizado constantemente, y que dependerá de las noticias que se vayan produciendo y no del número de tiradas que se han de imprimir.

\section{FUNCIONES QUE DEBERÁ DESARROLLAR EL PERIODISTA DE INFORMA - CIÓN ELECTRÓNICA}

Un periodista que trabaje con la información electrónica tendrá más ventajas que aquellos que lo hagan bajo la inspiración divina y sus dotes personales. Ahora, las posibilidades de presentar una noticia mas compactada son mayores. Podríamos pensar que no existe una noticia para una sola persona, sino que la información se trabaja de forma conjunta y en ella participan, además del redactor, el documentalista que cubre esa área y los lectores, que de momento son pasivos, pero a los que hay que dar una oportunidad en cuanto lleguen los periódicos personalizados.

27 F. Roger Fidler: "La desaparición de los medios de impresión digital". En: Commicaaón Social 1995/ Tendenias, Infames Anuales deFundesco, Madrid, p. 240. 
No hay unas funciones concretas como en el caso del DIE, pero el Periodista de Información Electrónica ha de contar con todos los aspectos de la noticia antes de comenzar su redacción, pensando además que ésta no finaliza cuando él acabe su redacción, sino que el concepto de actualidad constante, de inmediatez persistente, lo obliga a prever posibles modificaciones mientras el periódico no haya sido impreso.

Esta función es transcendental en el sistema de información que proponemos al hablar de periodismo personalizado, pues el autor de la noticia tiene para con sus lectores una responsabilidad que está obligado a actualizar constantemente, porque este tipo de periodismo está vivo, no termina muerto en un papel, sino que se rehace constantemente cada vez que van apareciendo nuevos datos.

Uno de los métodos de trabajo del Periodista de Información Electrónica es completar la información con el centro de documentación, para lo cual ha de seguir un doble camino: en primer lugar, antes de que se produzca el hecho noticioso, bien pasándose por el centro, o bien, si es que trabaja lejos de la redacción, mediante una solicitud concreta; y en segundo lugar, pidiendo una información de urgencia, dependiendo de los acontecimientos en los que se ha desarrollado el acto. No siempre se pueden seguir estos dos pasos, pues acontece que a veces la información no está prevista, en cuyo caso sólo se puede pedir la información de urgencia, tras conocer todos los detalles de la noticia.

En todo caso, un periódico electrónico ofrece información personalizada gracias a la posibilidad técnica de hacerpartícipe al lector en la elaboración de la misma, bien porque sea un experto en ese campo, o bien como un apoyo a los datos que ha conseguido el redactor del periódico.

En este proceso, el Periodista de Información Electrónica puede en todo momento cambiar la información, añadir, explicar o completar, siempre y cuando no haya enviado el texto al ordenador central desde donde los lectores toman las informaciones. Además, el redactor jefe puede también modificar la información desde su puesto, con un passwardde entrada.

Este sistema se ha empleado en algunos periódicos con las informaciones que llegan desde las agencias de noticias. É stas ofrecen la posibilidad de enviar sus productos separados, de tal forma que cada sección o apartado del periódico recibe sólo aquellas que tienen que ver con su área de trabajo, lo cual simplifica el proceso de búsqueda cuando un redactor intenta llegar a una noticia.

Pero además, el PIE puede emplear este dispositivo para recibir sus propias colaboraciones, es decir, los trabajos de gente que no es fija en la redacción pero que envía informaciones para completar una noticia. Si además esa persona es competente no sólo en el tema que domina, sino en las técnicas de redacción, la página estará prácticamente acabada en unos minutos, en cuanto el coordinador de esa sección termine con su trabajo.

Esta forma de presentar la información, como si fuera-en realidad lo es- lafirma deun especialista, no es sino un paso en el periódico que está por llegar. La compaginación de las páginas puede modificarse cada día o pueden intercambiarse las de 
diferentes secciones; si nos fijamos en un periódico éstas son casi siempre las mismas y sólo excepcionalmente cambian cuando una información gráfica asílo requiere. Tenemos, por tanto, una página lista para llenarla de información. En el periódico tradicional, es decir el que se hace en papel, se irían colocando las diferentes informaciones, al mismo tiempo que se modificarían las medidas si una noticia lo requiriera, pero siempre tendríamos la figura del intermediario, aquel que organiza o coordina la página. Seguimos trabajando con información electrónica, ya que exceptuando la parte que el redactor jefe ha escrito directamente -y ésta también se puede considerar electrónica- , el resto ha llegado a través de una línea telefónica y se ha almacenado en un soporte óptico o magnético.

¿Cómo actúa entonces el PIE? A provechando todas las ventajas que le ofrece la información electrónica. Y a no hay una persona que se encargue de la página, al menos materialmente. Ahora cada parte de la misma tiene un valor cambiante que determina cada colaborador. Existirá siempre una información dominante que ocupará la parte más importante de la página hasta que aparezca otra que merezca ocupar ese espacio, y el resto se llenará con noticias más cortas, colocadas en diferentes ángulos o columnas de esa página.

El PIE estará atento a buscar en cada momento nuevos detalles de la información sobre la que trabaja; detalles quetienen quevercon los aspecto s concretos delapropia noticia. D el resto se encargará el D ocumentalista de Información Electrónica, que irá leyendo cada vez que se introduce una nueva información en su pantalla y, a la vez, se encargará de variar los apoyos documentales que requiera esa información. Será unalabor constante de actualización. A demás, mientras el periodista sigue puntualmente los diferentes aspectos que van apareciendo en la información, el redactor jefe va recibiendo noticias al margen de los especialistas, quienes las han introducido en la página correspondiente, en la que éste ha de valorar si los contenidos se ajustan a las propuestas editoriales del periódico.

Este problema no se plantea en un periódico personalizado en el que la página está abierta a todos y en la que los responsables de la misma son los autores que firman el texto, conscientes de que su especialización los obliga únicamente a emplear un lenguaje común que pueda entender la mayor parte de los lectores, aunque el medio de comunicación para el que escriben tenga un carácter especializado, puesto que a estos periódicos que están en red puede llegar cualquier lector.

En ambos casos hay un trabajo de documentación que ahora ya no controla el PIE. Si el documentalista se encarga de vigilar la información que llega para completar con los datos que hay en el centro o en otros lugares donde puede conseguir información, el método de su trabajo se amplía unavez que cada colaborador vaintroduciendo también diferentes puntos de vista, sobre todo porque algunos modificarán su propio trabajo, e incluso el del redactor. Así, el documentalista tendrá que añadir nuevos apoyos documentales cuando la respuesta de un colaborador haya matizado algo diferente a lo que se explicaba anteriormente. 
Todo este proceso puede influir en los propios especialistas, a quienes les puede aparecer un nuevo punto de vista cuando desde el centro de documentación se añadan datos. D e esa información, de lo acertada que sea, va a depender que el resto de la información contenida en esa página tenga más o menos movilidad e interés para el lector.

Esto no quiere decir que la responsabilidad última de la página la tenga ahora el DIE, aunque sí una parte importante. Si hasta ahora la documentación sólo servía para que el redactor tomara unas ideas y las hiciera propias 0 , a partir de ellas, redactara unas nuevas; con la información electrónica volcada al instante sobre la página sucede lo contrario, pues pasan a ser partes de la información, con opción a crear nuevas informaciones. La documentación se convierte así en una fuente de información directa, como lo ha sido el hecho noticioso para muchos lectores.

La información electrónica posibilita un marco común para dar información en periódicos personalizados, en los que el centro de documentación tiene unafunción prioritaria de autoformación y de formación para el resto de participantes de la página. Es una aportación que nunca antes se había considerado pero que ahora adquiere el valor de noticia porque forma parte del hecho noticioso y sin ella no se podrá decir que la información está completa.

Toda la información que se consigue en cada página dentro de un periódico electrónico encuadrado en una empresa, no llevado a cabo por un colectivo o por una o dos personas, conlleva criterios de evaluación para medir sus resultados. La información electrónica ha de generar el suficiente número de lectores para que la publicidad acuda en mayor número posible, lo que directamente implica una posición ventajosa para ofrecer espacio al anunciante.

Hay que considerar además el criterio social, político, religioso, etcétera, que defiende la publicación y dentro delos cuales se mueve, no sólo por sus propios intereses - los de sus accionistas o propietarios- , sino por los de sus lectores, que quieren una línea de información sin cambios bruscos, adaptadaalo que esperan recibir cada día.

En estas tareas no participa directamente el PIE, pero ha de seguir las reglas impuestas por su redactor jefe, o simplemente las que marca la propia empresa. No siempre sucede que los colaboradores, esas personas que ahora tienen su espacio propio en cada noticia importante, deban ajustarse alas normas impuestas por el periódico; pero esto es enriquecedor porque de esta forma se le pueden encontrar varios aspectos a una información dentro de la misma noticia.

Será responsabilidad del PIE acercarse alas noticias que trabaja con una preparación importante, aunque sepa que contará con especialistas que le añadirán diferentes aspectos a la noticia que él aporta; el enfoque que debe llevar la noticia es obligación del periodista. Debe saber, además, que a la velocidad con que trabaja el periodismo electrónico los errores son difíciles de erradicar; por tanto, ha de centrarseal máximo en la redacción y concretar sus ideas en unos cuantos párrafos y desechar todo aquello que no tiene interés y que puede ser aprovechado por otro de los que intervienen en la misma página. En esta línea, habrá de constatar y confirmar 
cada dato que aporte, pues será a partir de éstos que actuará el resto de colaboradores, con lo que un error en su proceso informativo, bien en la recolección de datos 0 bien en la redacción, puede llevar a equivocaciones al resto de colaboradores y documentalistas que participan de su información.

Será regla de oro para el PIE una obligación inmediata y permanente, la redacción breve y clara del hecho noticioso, y la aportación de datos precisos sin dejar de lado ninguno de los aspectos que rodea una noticia. Sólo de esta forma se podrá considerar adecuada la otra información, aunque los colaboradores ya presenten otros aspectos parciales de la misma.

Por tanto, de la constante evolución informativa que tiene que hacer presente el PIE, no se salva ninguna de las partes que trabajan para realizar una información completa y en constante evolución, ni siquiera los lectores, quienes pueden contestar y abrir un nuevo foco de discusión en torno al hecho noticioso original.

En todo caso, el periodista ya está a la altura del documentalista, pues desde cualquier parte puede enviar información para esa página, consciente de que los apoyos documentales serán recibidos sin tener ni siquiera una comunicación directa entre ambos. Cada uno sabe lo que ha de aportar en cada página, se trata de un proceso conjunto que ha acercado de forma singular a estas dos disciplinas, que nunca debieron caminar por separado: la información y la documentación.

\section{LA FIGURA DEL NUEVO COMUNICADOR}

D entro de este proceso generalizado de la información electrónica, en la que se trabaja para crear información, hay tres pilares básicos: el periodista, el documentalista y el especialista en esa materia. Hemos de considerar que la evolución de las tecnologías y la formación académica que pueden recibir estos participantes, pudiera terminar en un sólo actor o protagonista de la noticia.

Si lallegada de las publicaciones periódicas convierte inicialmente al periodista en la persona que ha de elaborar la información, muy pronto en esa tarea empezó a participar el documentalista, aunque aún no se reconociera esa profesión. Al principio hemos constatado que era el propio periodista quien se encargaba de completar la información; con el paso del tiempo y ante la imposibilidad de controlar todos los aspectos de la noticia, otro periodista se encargó de elaborar biografías, informes, necrológicas, etcétera, con el fin de que la persona que tenía que redactar tuviera a su disposición los diferentes aspectos de la noticia que quería crear.

Fue la gran cantidad de noticias lo que imposibilitó un control por parte del periodista, porlo que poco a poco fue naciendo la figura del documentalista en los medios de comunicación para tratar y analizar las informaciones que iban apareciendo en los periódicos, es decir la producción propia, y para conseguir de otras fuentes aquellos datos que podían completar mejor la información. 
Además, la acumulación constante de información y la cada vez más numerosa publicación de informes, trabajos de investigación e incluso simples publicaciones que incluían ideas importantes para obtener conocimiento de cualquier campo, obligó a las empresas de prensa a crear centros propios que trabajaran con todo ese material, con una única idea: prepararlo cuando lo solicitara el redactor.

Ésa ha sido y es la tarea de un centro de documentación en prensa durante todo este siglo, servir de apoyo a las necesidades informativas del redactor. Pero no siempre se podían cumplir las exigencias de quien demandaba la información. En algunos casos no estaba bien ordenada y por tanto era imposible recuperarla; en otros, no se había hecho una política de selección adecuada y se había rechazado, y en ocasiones estaba en algún sitio pero quien la había utilizado por última vez no la había devuelto al lugar correcto. El centro de documentación periodística justificaba con éstos y otros trabajos la necesidad que tenían los periodistas para redactar, sobre todo, porque la memoria humana tiene un límite y no siempre se acuerda uno de todos los nombres o lugares.

Con el tiempo, la documentación justificó su valory los periódicos le dieron más importancia a su trabajo. Primero, considerando al documentalista como una persona con suficiente capacidad informativa como para entrar en sintonía con el redactor y atender sus posibilidades; en segundo lugar, considerándolo como fuente de información constante de los redactores, y en tercer lugar, como fuente de ingresos extraordinarios, ya que podían venderse productos documentales elaborados a partir de una materia prima ya creada por los redactores.

La documentación se convirtió entonces en un aspecto importante de la información. Podemos afirmar que ambas viven paralelamentey que su proceso de creación es similar. El único aspecto que entonces podía considerarse como disonante era que a la documentación se la consideraba como una parte de la información, pero no en todos los casos ni todos los redactores.

Así, el centro de documentación no podía competir con lainformación, ni siquiera con su propio sistema de trabajo. Cada vez con más frecuencia se iban acumulando documentos que terminaban por ser inservibles. Los redactores solicitaban apoyos que llegaban tarde o no llegaban, y su frustración fue aumentando.

Y como en todos los aspectos que hemosido presentando en este libro, la llegada del ordenador, y sobre todo de las memorias ópticas, cambió de forma radical el trabajo y los resultados del centro de documentación periodística. Si a todo esto añadimos un personal cualificado y preparado, conocedor no sólo de las nuevas tecnologías sino de los aspectos más importantes de la información, llegaremos a unos resultados óptimos y que modifican la estrategia de los redactores respecto delo que pueden lograr si consultan el centro de documentación.

Así, hemos de fijarnos en este aspecto concreto de la importancia de las nuevas tecnologías. En primer lugar, la recuperación de la información la podía hacer el propio periodista. D esde el centro se confeccionaron bases de datos fáciles de consultar y que permitían respuestas más o menos inmediatas. De esta forma, aquellos 
datos que antes se consultaban manualmente en la sección de referencia, ahora se tenían listos en la pantalla del ordenador en muy poco tiempo. En segundo lugar, los datos que requerían consultas especializadas se hacían también en un tiempo menor y con resultados más concretos, con lo que las referencias que se entregaban alos redactores eran menos y más precisas. En tercer lugar, al centro de documentación llegaban una serie de noticias que, una vez elaboradas, facilitaban enormemente el trabajo, con lo que la imagen del redactor hacia el centro varió sustancialmente.

Más importante fue, a nuestro juicio, el hecho de que la documentación que generaba el propio periódico se pudiera tratar de forma inmediata recuperando páginas enteras y, consecuentemente, bloques de información que más tarde iba a solicitar el propio redactor. Si la especialización impuesta desde los años ochenta obliga al redactor a estar trabajando sobre el mismo tema durante un tiempo considerable, - juicios que se alargan, crisis financieras que no encuentran solución, etcétera-, la aportación del centro de documentación es decisiva para no repetir conceptos 0 para avanzar un poco más en la última línea de trabajo que abordó. Hay que pensar que no es difícil repetir ideas e incluso artículos enteros creyendo que aún no se habían publicado, lo que crea en el lector una sensación de inseguridad ante el periódico que lee. Pero éste problema tiene solución, al menos ahora que las nuevas tecnologías le permiten al redactor adentrarse en el centro de documentación y consultar todo aquello que se ha publicado sobre un tema.

Esta vía abierta nos acerca a otro aspecto necesario que hay que tratar. Si el periodista puede acceder directamente a la información ¿cuál serála función del documentalista? Podríamos pensar que éste desaparecería, que regresaríamos a los primeros momentos de las publicaciones periódicas en las que el mismo periodista ejercía las dos tareas. A demás, si las nuevas tecnologías permiten entrar con suma facilidad, dada la simplificación de algunos lenguajes documentales, en las diferentes fuentes de información, el redactor podrá preparar su información sin ayuda de nadie.

E sa pregunta, sin embargo, tiene otras consideraciones. Si el redactor llega con tanta facilidad a buscar esas respuestas es porque técnicamente es posible, pero también porque antes un documentalista ha confeccionado esa base de datos que ahora permite recuperar el texto. A demás, el periodista tendrá que estar atento a posibles modificaciones del hecho noticioso, y dejarle la parte de apoyos a un documentalista.

Pero hemos de centrarnos en esta idea. Estamos hablando de información electrónica que pronto dará paso a la información personalizada. Bajo este prisma, en el que los contenidos cambian constantemente y siempre dependiendo de los acontecimientos que se vayan produciendo, el planteamiento que hemos defendido al describir las funciones del Periodista de Información Electrónica se basa en una constante actualización de la información, según se vayan produciendo los hechos, con lo que no tendrá tiempo de ampliar la información que, como también hemos constatado, correrá a cargo del D ocumentalista de Información Electrónica y de los colaboradores o especialistas en ese campo. 
No resulta fácil hacer predicciones, pero hemos de considerar tres aspectos importantes que nos servirán también como conclusiones:

1.- El documentalista se ocupa de tareas exclusivamente documentales. Es, por tanto, o mejor dicho, sigue siendo una figura decorativa a las órdenes del redactor con quien se mantiene en contacto para que le resuelva las dudas, porque el redactor trabajará lejos de la redacción.

En este sentido, seguirá ejerciendo tareas como la selección de documentos, su análisis y el resumen de los mismos, así como la preparación de informes y dossiers para los redactores, con lo que se habrá desaprovechado un trabajo importante que puede desarrollar porque se siente capacitado para ello y que consiste en aportar de forma directa aquellos resultados que completan la información, sin que para ello tenga que intervenir el redactor.

2.- El periodista se encarga de todo el proceso, algo que es impensable aun cuando las tecnologías le permiten acercarse a una gran cantidad de documentos. Este es el problema principal, que los documentos son de tal magnitud que si no hay alguien que los prepare se habrá perdido el tiempo necesario que un periódico personalizado exige para competir con otros de su misma categoría. Por tanto, el periodista se ve incapacitado y alguien puede complementar lainformación; y quien más facilidades tiene es el documentalista.

3.- El nuevo comunicador sería aquella persona que aprovecha la información porque conoce el proceso informativo y porque ha trabajado también en el campo documental, y que elige lo que puede interesarle al lector y desecha aquellas ideas que puedan confundirlo.

Q uizás en un futuro no muy lejano, porque las predicciones cada vez hay que hacerlas a más corto plazo, tengamos que pensar en la figura de un nuevo comunicador, una persona que beba en las fuentes documentales, conozca las herramientas necesarias de lainformación, y redacte de forma clara y sencilla para que los contenidos lleguen a los lectores. ¿Podría hacer esto un documentalista? ¿Un periodista sin ayuda del centro de documentación lo conseguiría? En ambos casos podemos contestar afirmativamente, aunque con reservas.

Un documentalista está acostumbrado a trabajar con fuentes documentales, de las que obtiene los datos que necesita para trabajar. Es parte de su tarea seleccionar los aspectos más importantes, en el caso de resúmenes, o todos, si la referencia es a texto completo. Además, el documentalista no es ajeno a una redacción clara y concisa cuando tiene que presentar resúmenes documentales o informes en unas cuantas líneas.

Si nos fijamos detenidamente, podemos concluir que un documentalista está capacitado para ejercer las labores que normalmente hace un periodista; no en vano, aunque con matices, el proceso informativo y el documental sigue un camino paralelo; aunque quizás al final el usuario documental no siempre se conozcay el lector quizá sí, puesto que existe una afinidad demostrada de los lectores a un mismo periódico. En este sentido, podríamos invertir la pregunta ¿podría un periodista ejercer funciones de 
documentalista? No es necesario que busquemos una solución, puesto que el actor principal de la información es el redactor y de nada serviría que perdiera el tiempo ejercitandose en la tarea que otra persona puede desempeñar con mejores resultados. D e todas formas, si continuara el proceso informativo tampoco tendría un periodista demasiados problemas para desenvolverse en el centro de documentación.

$\mathrm{Si}$ el documentalista puede ejercer labores de periodista y a la inversa, lo ideal es que en un futuro aparezca la figura de un nuevo comunicador: la simbiosis de un buen documentalista y un buen redactor. Será una formación complementaria en ambos campos, pero también difícil de separar, puesto que como estamos proponiendo la llegada de la información personalizada obliga a cada uno a ejercer tareas similares, aunque concretas: el periodista cuenta los datos que se van produciendo de un acontecimiento y el documentalista amplia esta información desde el centro. Ambos actualizan su información conforme el redactor va aportando nuevos datos 0 , en algunos casos, cuando desde el centro de documentación se detecte un nuevo aspecto de la información. En ese sentido, el redactor, que sigue en contacto permanente con su página y que acaba de leer la información que ha introducido el documentalista, puede investigar esa nueva perspectiva para aportar nuevos datos.

$\mathrm{Si}$ ambos tienen delimitadas sus acciones en una información, el tercer actuante, el colaborador, es quien tiene el campo más abierto, pues añadirá a sus cono cimientos personales aquellos otros que tendrá que buscar de forma inmediata para que su opinión con respecto al hecho noticioso tenga un punto de vista interesante y pueda permanecer durante un tiempo en la página. Se supone que las diferentes entradas de información no tienen por qué afectarle, puesto que si el colaborador, el especialista, forma parte del equipo, es porque está preparado para comentar aspectos que la propia información no genera, pero que sí tienen quever con ella. Además, está la figura del especialista en el ámbito diferente del colaborador o usuario. Cada uno tiene su parte a la hora de confeccionar la información.

Hay una consideración más que tenemos que analizar. Cuando hablamos de información personalizada lo hacemos pensando en que no habrá un único periódico sino que serán varios en cada campo, y que lo que atraerá a los lectores será no sólo su presentación gráfica, algo fundamental en estos soportes que permiten un gran tratamiento delaimagen para acompañar a la información, sino también lo que pueden decir los expertos, personas preparadas intelectualmente en ese campo.

Esta competencia obligará a tratar la información de una manera más viva. Los periódicos tendrán que vivir de la publicidad, puesto que la venta será impensable, a no ser que se solicite un passwad, y sería ridículo cobrar un precio tan pequeño por una labor que tanto cuesta desarrollar. En este caso, para que la publicidad acuda al periódico, éste tiene que demostrar que los lectores que dice tener son tales. Se acabará el baile de cifras en torno al número de lectores que aseveran tener los periódicos cuando alguien les va a ofrecer publicidad. Ahora técnicamente será factible saber cuántos lectores han acudido al periódico; aunque habráun problema, no sabremos si es siempre la misma persona que se conecta una y otra vez, o cada conexión corresponde a un 
lector diferente. En todo caso, será más fácil saber el número de personas que han entrado en el periódico personalizado. Más aún, se puede medir qué tipo de noticias ha leído cada uno de ellos y, consecuentemente, ir acercando los intereses del periódico a las necesidades del lector.

O tro de los aspectos en los que no participa de forma directa la figura del nuevo comunicador, será el nacimiento de una multitud de periódicos personalizados que se aprovecharán de las informaciones que existan en la red y tengan carácter gratuito. Estos medios, que tendrán el nombre de una persona o de una institución, se dedicarán a ofrecer informaciones concretas y puntuales y sobre todo servicios que pueden interesar a las personas con las que convive el autor. Podría ser que la mayoría fueran periódicos temáticos, dada la facilidad que confiere el trabajar siempre sobreel mismo tema; o de carácter general, cuando los horizontes de lectura se quieran ampliary conlleven la consiguiente exigencia de abarcar más aspectos informativos, más personas para hacerlos y más gastos, aunque se espera que la publicidad también sería mayor.

En estos casos, incluso en este tipo de periódicos, existirá la figura del nuevo comunicador, la persona que ha puesto en marcha el proyecto y quien se encarga de sa carla información de la red para colocarla en su medio y quien distribuye el espacio entre sus lectores, quienes a su vez tendrán la oportunidad de escribir en torno al tema en el que se mueve ese periódico.

Esta dispersión informativa no favorece en nada a la documentación. Se crea una mayor literaturagis lo que implicaun esfuerzo excesivo si se quiere tener en el centro de documentación una cantidad importante de la información sobre periodismo. O tra de las tareas, por tanto, del D ocumentalista de Información Electrónica, será rastrearla red en la que se encuentran esos periódicos para recoger posibles informaciones que puedan interesar a los redactores de su propio periódico.

No es una garantía que todo lo que encuentre el documentalista pueda ser interesante, pero el trabajo documental deberá hacerse con rigor para no dejar fuera aspectos importantes que luego puedan ser decisivos a la hora de redactar una información y que el periódico de la competencia pueda aprovechar.

En esa convivencia entre periódicos personales, hechos por y para una persona, y los de información general, - con su propio centro de documentación trabajando para ofrecer la mejor información- el lector determinará cuándo y por quéelige uno u otro. Pese a que cada día o, mejor dicho, a cada momento se están constituyendo nuevos periódicos, lo que sí podemos confirmar desde ahora es que el lector tendrá un periódico personalizado propio, que leerá cada día, como antes lo hacía con el que aparecía en papel, y además otros más especializados con base en sus gustos: deportivos, taurinos, gastronómicos, etcétera.

Cambian, pues, los métodos de presentar la información, se exige un comunicador que comprenda las funciones documentales y una mayor presencia de colaboradores que conozcan a fondo el campo en el que se desenvuelven. Quien disfruta al final es el lector, que de ser considerado como un simple actor pasivo, se convierte 
en un personaje decisivo, puesto que además de dar el sí o no cada día, mediante una conexión al periódico, ahora tiene la oportunidad de ocupar él otros espacios además de las simples y escuetas cartas al director que permitían los periódicos impresos. Si de las tareas informativas participa un documentalista y si el periodista saca provecho de los datos que hay en el centro de documentación, el producto resultante tiene que ser de mejor calidad y precisión que el que se venía presentando hasta ahora.

Hemos presentado la información electrónica como paso previo para llegar a la información especializada, en la que estos dos actores que se constituyen en el nuevo comunicador nos presentan el periódico personalizado. Pero antes, hemos de considerar, aunque sea de forma somera, un aspecto del periodismo que contribuyó de manera notoria a estructurar los contenidos de la información y que ha sido fundamental parallegar alainformación especializada. Nos estamos refiriendo al periodismo de precisión.

\section{BIBLIOGRAFÍA}

A GULLÓ, E.: "Alto nivel de equipamiento tecnológico de la prensa diaria española”. En: NcticiasdelaCommicacón, №13,1991.

BECKETT, Andy: "Más cerca del periódico por ordenador". The Independent-El País En: El País, 13 de mayo de 1994.

BENS, E. de: "Reciente evolución de los medios de comunicación electrónicos en la CEE". En: MundbEletrónica 1989.

BEZUNARTEA, O fa: Laprensaanted cambiodesiga Bilbao: D eusto, 1988.

CAPELLA, D aniel: “Los nuevos medios electrónicos amenazan la supervivencia de los diarios". Bajado de LaV angrardiaEletró nica, 6 de noviembre de 1997.

COD INA, Lluis: "Periodismo digital en Internet". En: Byte Marzo 1996.

FID LER, Roger F: "La desaparición de los medios de impresión digital" . En: Commicadón Social 1995/ Tendenias, InfomesAnuales deFundesca Madrid.

FRANQ UET, Rosa: "La sacudida digital: Escenarios de una transformación acelerada”. En: CommicacónSocial 1995/ Tendenias, Infomes Anuales deFundesco, Madrid.

MARCOSRECIO, Juan Carlos: "Eldocumentalista de información electrónica”. En: Doumentación delas Cienias dela Informacón Faailtad deCienaias dela Infomacón. DepartamentodeBiblictecono máayDoumentación, №19.

MAY ORALAS, Miguel Benito: "La redacción electrónica”. En: Re vista Fundesco, nun. 47. 
NEGRO PO NTE, Nicholas: El mundodgital. Barcelona: Ediciones B, 1995.

O LIVIÉ, Antonio: “El periódico ala carta”. En ABC: 6 de febrero de 1994.

PARTAL, Vicent: "Vayan dejando los papeles". En: El PeiódicodeCataluña, 1 de mayo de 1995.

Ko YRE, Alexandre: Estudios dehistaria de pensamiento científica Madrid: Siglo XXI, 1990.

RECODER SELLARES, María José; Emest Abadal, Lluís Codina: Infomacón detrónica ynuevasteendoǵas Barcelona: PPU, 1991.

Ruíz D E ElVIRA, Mariló: “The New York Times”, elegido el mejor diario en Internet. En: El País, 17 de febrero de 1997.

- - - : "En pugna con los diarios. World Media Network”. En: El País, 18 de diciembre de 1997.

SLO UKA, Mark: Warofthewords, Cyberspaceand thelightechassaultonreality. Basic, Harper-Collins, Nueva Y ork, 1995.

SChWARTAU, Winn: "El futuro no es como lo pintan". World Media Network. En: El País 18 de diciembre de 1997.

TERCEIRO, José: Sociedad Digital. De ham sapiens al hamo digtalis Madrid: Alianza Editorial, 1996.

TREJO D ELARBRE, Raúl: Lanuevalfonbramágica: Usosymitos deInteme. Madrid: Fundesco, 1996.
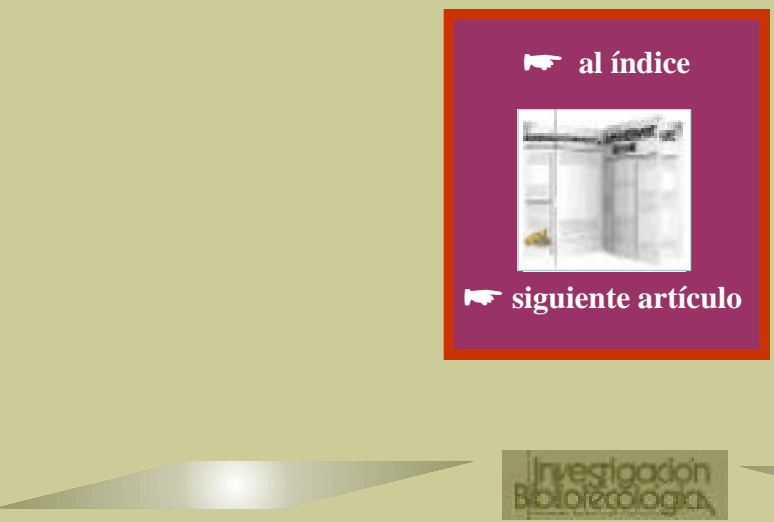